\title{
Economic preferences in the classroom - research documentation
}

\author{
Dániel Horn $^{(\mathrm{a})(\mathrm{b})}$, Hubert János Kiss ${ }^{(\mathrm{a})(\mathrm{b})}$, Tünde Lénárd ${ }^{(\mathrm{a})}$
}

May 30, 2020

\begin{abstract}
In this paper, we document how we carried out a research that aimed at measuring the economic preferences of high school students. We describe the preferences that we study and what experimental games we used to investigate them. Then we report how we carried out the experiments in the schools. We provide detailed descriptive statistics on the preferences in aggregate and also school by school. Last, we validate our measurement by comparing the measured preferences to those in the literature.
\end{abstract}

Keywords: altruism, competitive preferences, cooperation, risk preferences, social preferences, student, time preferences, trust

JEL codes: C70, C80, C90, D91, J16

Funding: The project received funding from the Hungarian National Research, Development and Innovation Office, grant number K-124396.

(a) Institute of Economics, Centre for Economic and Regional Studies, Budapest, Tóth Kálmán utca 4, H-1097, Hungary

(b) Corvinus University of Budapest, Hungary 


\section{Introduction}

From March 2018 to March 2020, we visited 10 secondary schools in Hungary to measure the economic preferences of students. This paper documents how we carried out the measurements, what issues arose and how we solved them. We also present detailed descriptive statistics and perform a validation exercise. Overall, we measured time, risk, social and competitive preferences of 1276 students in 71 school classes (groups of students studying the major subjects together). As we will show, the correlations between the measured preferences and the associations between the preferences and socio-demographics of the students are in line with those reported in the literature.

The project has been funded by the National Research and Development Office of Hungary (project no. 124396). The experiments were run in Hungarian, and also the related legal documents are available in Hungarian here: https://www.mtakti.hu/kapcsolat/altalanos-tajekoztato-akiserletekrol/.

The experiments were anonymous, but we can link the individual preferences with the individual data from the National Assessment of Basic Competences (NABC) - see more details below - which allows us to see how preferences relate to individual school performance, aspiration and other school characteristics (type of class, curriculum, location, etc.). It also provides us with useful information about the participants' family background. With the detailed preference map of the students and the additional information on their family background and school performance, we want to study several research questions. For instance, we are interested in the distribution of preferences between and within schools, how family background associates with preferences, the association of past school performance and recent preferences, the mediating power of family between past school performance and preferences. Since we have school-class level data, we can also study if classes with better aggregated social preferences perform better academically. That is, do classes where students are more generous, cooperative and trusting exhibit better academic results? 
In this report, we present only the descriptive statistics of the data that we have collected and defer the more detailed statistical and econometric analysis to future research papers.

\section{Preferences and experimental games}

In the last decade, the study of adolescents' preferences has become a very intense field, mostly aiming to understand how those preferences affect school performance and behaviour or later life outcomes. Most of the studies in this literature focus only on a limited set of preferences (see Sutter et al. 2019, for a survey of the literature). If the preferences are correlated, then a separate measurement of them and inferences drawn from those measurements may lead to incorrect conclusions. For instance, the measurement of time preferences involves the choice between amounts of money to be received at different points in time. However, since the future is inherently risky, these intertemporal choices may be affected by risk preferences as well. Similarly, entering a competition is a risky choice. People, who are risk-averse, might be opting out from competitive situations, even if they would not shy away from competition, ceteris paribus.

Our goal was to obtain a more comprehensive picture of the preferences of the participants. Therefore, we chose to measure the most basic and widely studied preferences: time, risk, social and competitive preferences. Social preferences include generosity (also known as altruism), cooperation and trust. Overall, students participated in 8 experimental tasks, so we have a detailed dataset that allows us to obtain a fairly accurate map of preferences. With this set of preferences, it is possible to pin down the effect of separate preferences because we can control for the effect of the other ones.

\subsection{Procedures}

We conducted our computer-based experiment in 71 classes in 10 schools. Before starting the project, we contacted all educational providers in Hungary with at least one secondary school (academic, vocational or mixed) to request permission to run the experiment in their institutions. 
Providers with only Special Vocational Schools were left out (see Lénárd, Horn and Kiss 2020). The schools included in our sample were either suggested by the provider or - given the positive feedback from their provider - they voluntarily indicated their willingness to participate. Five of them operate in Budapest and five in smaller rural towns of Hungary. To maintain the anonymity of the schools, we use acronyms, see Table 1.

\begin{tabular}{|c|c|c|c|c|c|c|c|c|c|c|c|}
\hline & $\mathrm{FB}$ & $\mathrm{KB}$ & KB2 & KK & KSZ & MK & $\mathrm{NE}$ & $\mathrm{PB}$ & Pilot & SZB & Total \\
\hline $\begin{array}{l}\text { Academic or vocational } \\
\text { secondary school }\end{array}$ & Ac. & Ac. & Vs. + Ac. & Ac. & Vs. + Ac. & Vs. + Ac. & Ac. & Ac. & Ac. & Ac. & \\
\hline 2018 & 0 & 0 & 0 & 0 & 0 & 0 & 0 & 0 & 18 & 0 & 18 \\
\hline 2019 & 4 & 10 & 4 & 0 & 0 & 5 & 4 & 4 & 0 & 4 & 35 \\
\hline 2020 & 6 & 0 & 0 & 7 & 5 & 0 & 0 & 0 & 0 & 0 & 18 \\
\hline Total & 10 & 10 & 4 & 7 & 5 & 5 & 4 & 4 & 18 & 4 & 71 \\
\hline
\end{tabular}

Note.: Ac. - academic, Vs. - vocational secondary

Table 1. School classes by school and year

Naturally, our sample of schools is not representative of the total school population of Hungary, as we went mainly to academic tracks and a few vocational secondary schools (offering maturity exams). Figures 1 and 2 compare our sample to the whole universe of such schools in Hungary in terms of socioeconomic status (captured by the highest level of education of the mother) and gender composition. Figure 3 compares $6^{\text {th }}$-grade math test scores of the students in our sample to the test scores of $6^{\text {th }}$ grade students in 2017.

Figure 1 shows that the socioeconomic status of the students that participated in our experiments is higher than that of the whole population as the share of students in our sample who have a mother with a tertiary degree is higher than the same share in the population. 


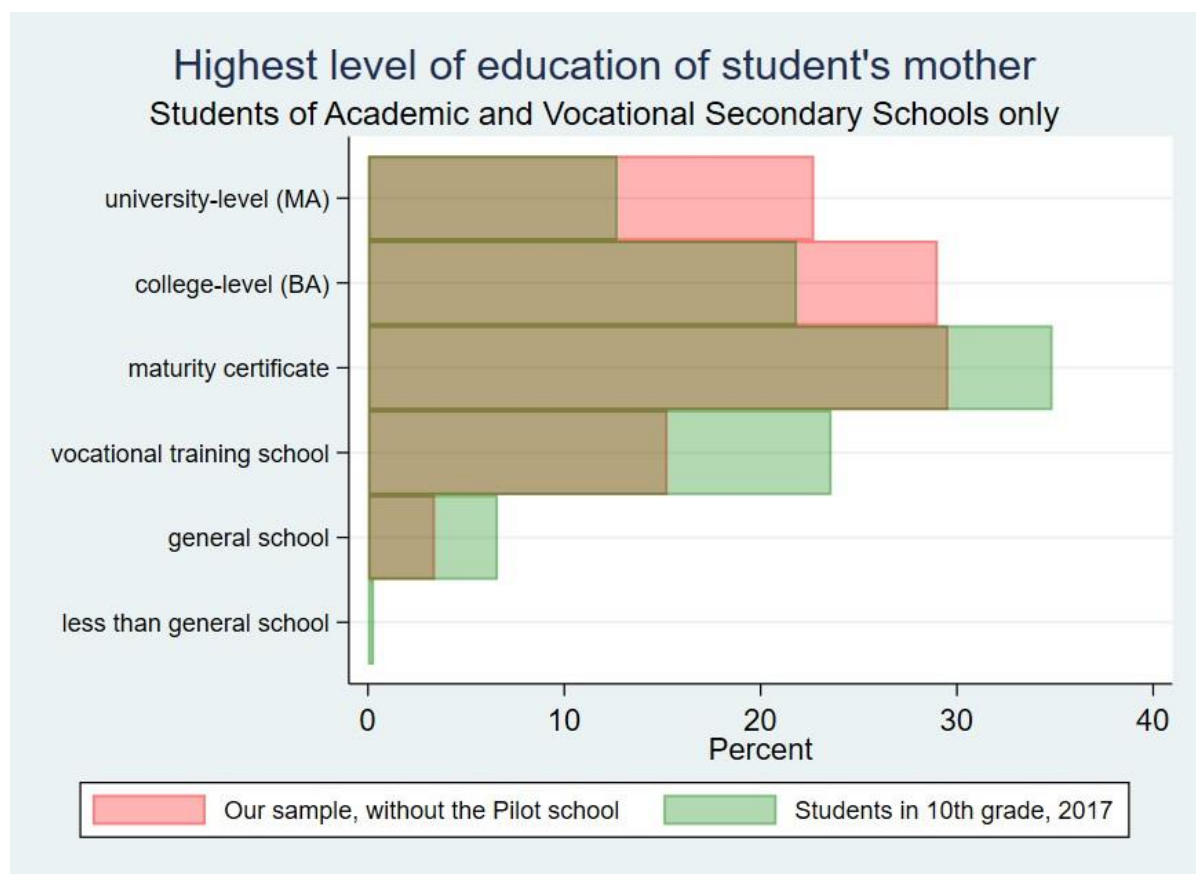

Figure 1. Distribution of highest level of education of student's mother in our sample and the population

Figure 2 shows that in terms of gender composition, the share of females is somewhat higher in our sample than in the population, but the difference is not pronounced.

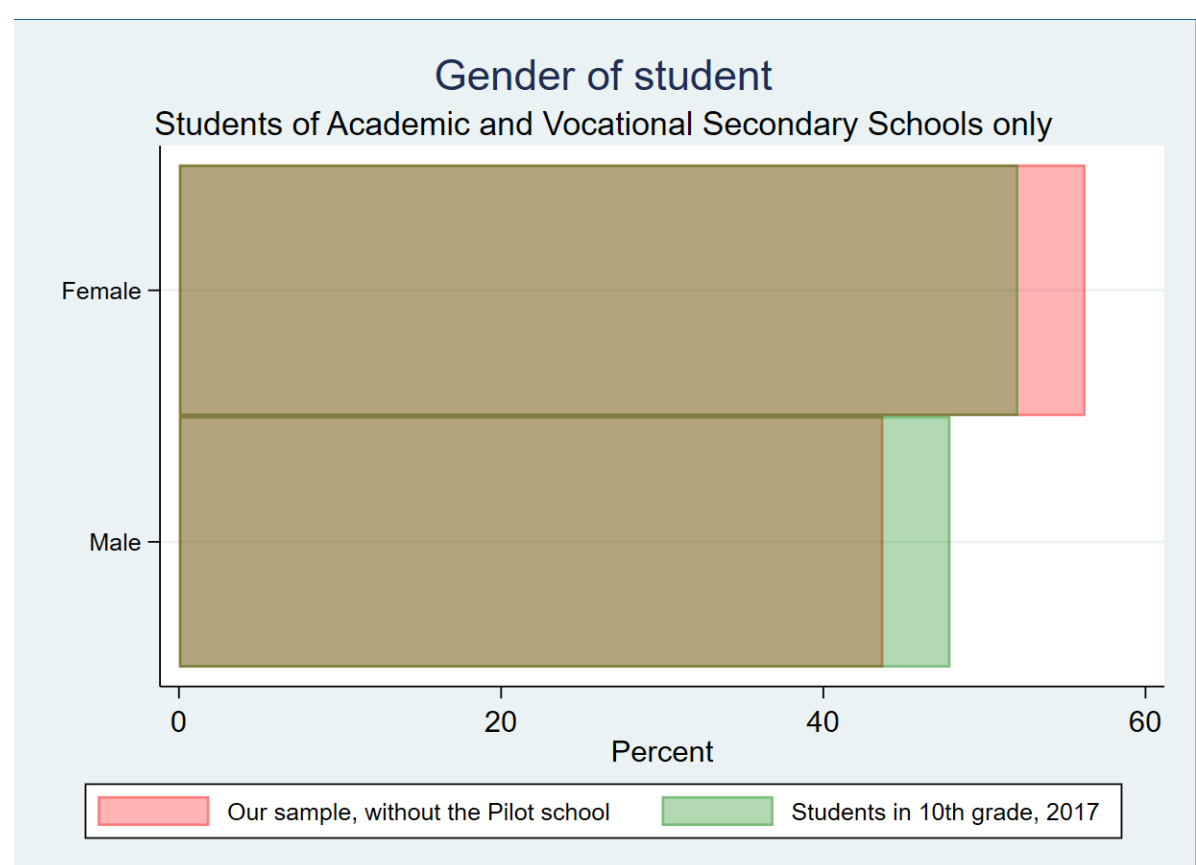

Figure 2. Distribution of gender in our sample and the population 
Figure 3 reveals that the mathematics test scores measured by the National Assessment of Basic Competences in $6^{\text {th }}$ grade are on average higher in our sample than they are in the population of all $6^{\text {th }}$-grade students in $2017 .^{1}$

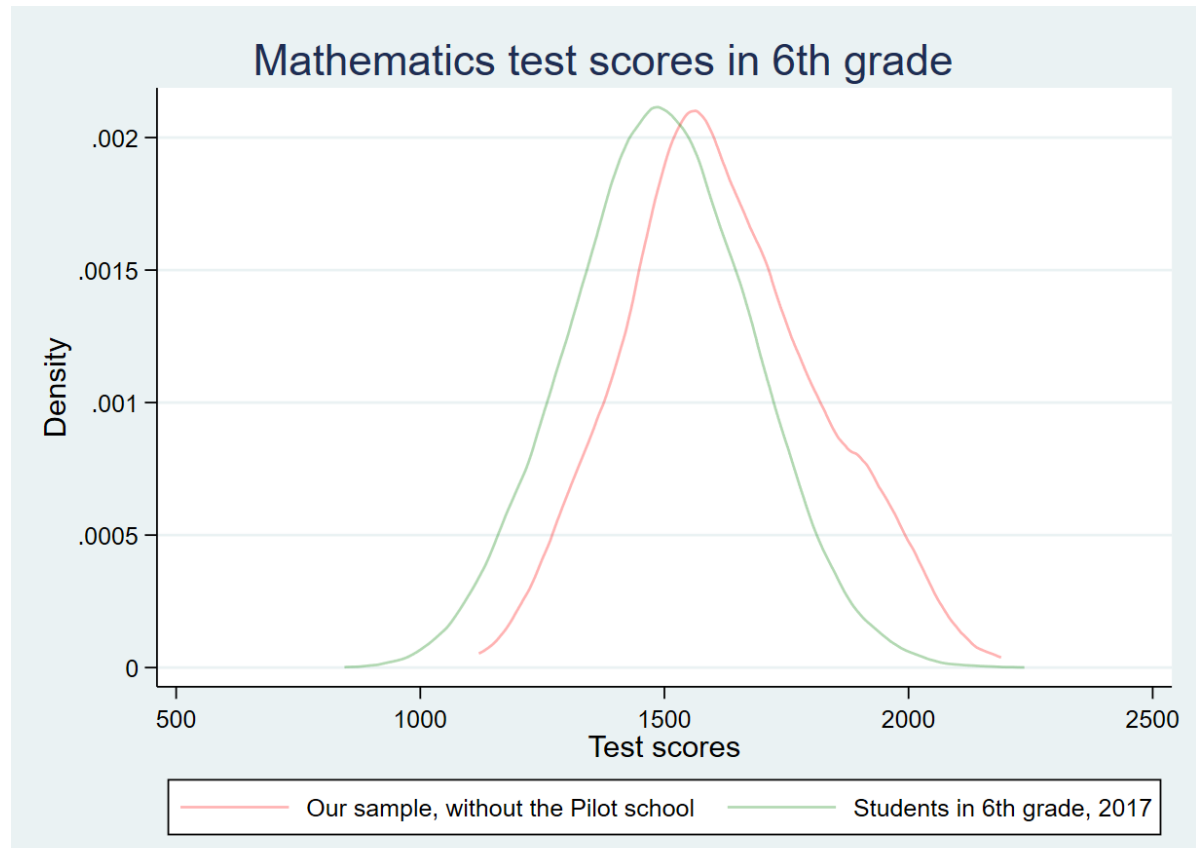

Figure 3. Distribution of test scores in 6th grade in our sample and the population

The experiments were conducted during school hours, with each session being roughly as long as a regular lesson. Since we went to the schools and carried out the experiment there, we had to adapt to the time schedule of the schools. In most Hungarian schools, classes are 45 minutes long, followed by a 15-minute long break. Thus, we had 45 minutes (at most 60 minutes) to run the experiment with a class.

Participation was voluntary and anonymous. We sent out the data protection statement to all parents and children prior to the assessment, notifying them that in our survey we ask for the students' IDs used at the National Assessment of Basic Competences (NABC) which allows us to connect our experimental data to anonymous NABC data on school performance and socioeconomic background at the individual level. Only two students have opted out from our experiments. The NABC ID is a hash-code of the educational IDs of the students, and is used only

\footnotetext{
${ }^{1}$ The difference is significant $(\mathrm{t}$-test, $\mathrm{p}<0.0001)$.
} 
to identify students within the NABC surveys but are otherwise not linked to any other datasets. Education providers had also been notified that we would collect NABC IDs, and none of them protested against this practice.

We asked the schools to distribute the NABC IDs to the students before the experiment on paper, which they had to take away after. Students could only start the experimental games after typing in their IDs, but no other individual data were asked. ${ }^{2}$

Participants were classmates in all sessions, which is an important feature in our experiment that allowed us to measure in-group and out-group favouritism (see section 2.4.1) as well as other class-level characteristics. Some of the tasks were individual tasks, where payoffs did not depend on the choices of other participants. Other tasks involved strategic interaction, so the decisions of two participants determined the payoffs. In these cases, the software that we used to program the experiment (z-Tree, Fischbacher (2007)) created student pairs randomly. Pairing always occurred at the end of the experiment, after obtaining information about each student's decision in each hypothetical situation. When we had an odd number of participants in the room, then the last „pair” of students was a group of three participants. In games that required interaction, the payments of students in the group of three were affected by the decision of only one of the other students in that group. This was also randomly determined by the program.

We used meal vouchers for the school cafeterias to incentivize the experiments. We explained to students that they would make decisions in 8 tasks, and at the end of the experiment, one of the tasks would be chosen randomly by the computer for payment (same for everyone in a session). Many of the tasks involved more choices. We made clear that in these cases, one of those choices would be picked randomly for payment. All sums were rounded to hundred Forints (the Hungarian currency) as we paid out the students in hundred Forints. There was no show-up fee, as

\footnotetext{
${ }^{2}$ There were some problems of the distribution of the NABC IDs in some classes in our sample. These groups got temporary IDs, so we are not able to link their preference data to the NABC database, hence some background data is missing.
} 
we have visited students in their school. We designed the payoffs so that the expected payoff would be around 1000 HUF (around 3 EUR). ${ }^{3}$

Participants were informed about the payout details (e.g. random selection of tasks and decisions for payment) right before each session and were paid after everyone in their school group had finished all tasks. If one of the two time-preference tasks was selected for payment (in which students had to choose between different sums of money paid at different times), everyone was paid according to their individual decision. The sums requested at the time of the experiment were handed out after the experiment. Students who chose to have another amount two, four or six weeks later had to put their vouchers in an envelope, which we placed at the school secretariat asking the management of the school to give out these vouchers two, four or six weeks later (as indicated on each envelope). ${ }^{4}$

On experiment day, we unpacked our laptops in the school in a designated classroom, turning it into our laboratory for the day. Participants used school computers in only two Budapest schools, which also meant using a mouse instead of a touchpad. In all the other cases, it was easier to bring our laptops with the necessary programs and settings, as schools have typically no or smaller labs.

When participants entered the room where we carried out the experiment, they were free to choose a seat. They had a sheet with the instructions in front of them. Once everybody seated, an experimenter read aloud this instruction sheet. Any questions from the students were answered. A shorter version of the rules appeared on the start screen of the experiment. Participants were assured that all decisions remained confidential.

\footnotetext{
${ }^{3} 1000$ HUF is around the cost of a full meal at a school cafeteria.

${ }^{4} \mathrm{We}$ were careful to choose dates for the experiments so that payments in 2,4 or 6 weeks can be received and that the vouchers could be used without any problem. That is, no later payment occurred during holidays. Note however, that the Covid-19 outbreak has impacted some of the later payments. We have agreed with the schools to distribute these later payments for the students when normal routine returns. Note also, as the outbreak and the imminent school closure was unexpected, this should not have affected the choices the students made.
} 
We did not impose time limits in the different tasks (except the real-effort task to measure competitiveness, see below) so the participants could take their time. The only constraint, as mentioned, was that we had to end the experiment before the next class. We also explained to the participants that potentially there could be large differences in how much it would take for different participants to choose in different tasks, and we asked them to be patient. In fact, there was large heterogeneity in the time that participants spent with the games, but we had no incidents due to having to wait for the others who needed more time to decide.

In all occasions, at least two experimenters were in the room to monitor if everything went smoothly. In the instructions, we warned the participants that we did not tolerate misbehaviour (speaking to others, looking at their screens etc.) and that such behaviour could be punished with expelling the misbehaving participant without any payments. Fortunately, no such punishments were needed, there was no major incident related to misbehaviour during the experiments.

It has not been obvious in which order our 8 tasks should be performed. We took into account the following considerations when establishing the order. We wanted to have the two time preference tasks apart, as participants might have unwittingly tried to be consistent by making the same choices had the two tasks been neighbouring. Since the two dictator games involved the same decision but with different reference groups, we put these questions close to each other. The only task that could have affected the emotions of the participants more intensely was the competitiveness task, as participants were placed in a competitive setup that some of them may not have liked. Moreover, feedback on their performance after each round were provided. In order to avoid that the experience in this task affects the choices in other tasks, we put the competitiveness task at the end. Regarding the rest of the experimental tasks, we did not give feedback to the participants between tasks to avoid that the outcome of a task affects choice in the subsequent tasks. 
To test if we can carry out the experiment properly, in March 2018, we went to the Pilot high school where we tested 18 different classes/groups of students, with differing sizes. Using this experience, we altered two of the initial experimental tasks. The first concerned the measurement of risk preferences that in the pilot were measured following Falk et al. (2018) gamble games, using the staircase method. Since gambles were not so natural for our subject pool, for the subsequent schools we opted for using the bomb risk elicitation task (Crosetto and Filippin 2013) that involves a story about a risky choice and seemed more appropriate for high school students. The other change was in the competitiveness task, where we changed the real-effort task. In the pilot, we used the slider task (Gill and Prowse 2019), but it was susceptible to the computer that participants used and participants with more computer experience performed better (mainly due to playing computer games). Hence, the task was not neutral enough for our purpose. Instead of this task in the rest of the schools, we used a different real-effort task consisting of counting zeros and ones in 5x5 matrices (see Abeler et al. 2011).

After each visit, we sent feedback to the schools. ${ }^{5}$ We explained briefly in the feedbacks, what preferences the different tasks measured, and we reported the main descriptive statistics, comparing them to the main findings of the literature. We also compared succinctly how different school groups performed.

\subsection{Time preferences (task 1 and 6)}

Time preferences express how an individual trades off earlier and later benefits and they are generally measured with choices that individuals make between an earlier and a later amount of money (see Andreoni et al. 2015; Cohen et al. 2016).

Time preferences have at least two relevant aspects. Patience reveals how an individual values the future relative to the present, while time consistency indicates if this relative valuation

\footnotetext{
${ }^{5}$ In case of two high schools in Budapest, they invited us to give a short presentation to the participants and the teachers.
} 
is the same at different points in time. Patient individuals value the future more relative to the present than their less patient peers. Time consistent individuals trade off earlier and later benefits in the same way at different points in time. In contrast, present-biased (future-biased) individuals are less (more) patient in the near future than later on. To capture both aspects of time preferences, we needed two different time horizons. Our participants had to choose between receiving a smaller amount today or a larger amount in 2 weeks (task 1) and they faced the same situation, but the dates were 4 weeks vs. 6 weeks (task 6). On both horizons, participants had to make 5 interdependent choices, following the staircase (or unfolding brackets) methodology (Cornsweet 1962). This methodology uses the available number of questions efficiently to zoom in on the indifference point between the earlier and the later payoffs. In each case, the earlier amount was fixed (1000 Ft) while the later amount $(\mathrm{X})$ was changed adaptively, depending on the previous choices. For example, if a participant chooses $1000 \mathrm{Ft}$ today instead of $\mathrm{X}=1540 \mathrm{Ft}$ in 2 weeks, then we know that her indifference point is higher than $1540 \mathrm{Ft}$, so in the next question $\mathrm{X}$ is increased. Similarly, the choice of the later amount implies a decrease in $\mathrm{X}$ in the next question. $\mathrm{X}$ varied from 1030 to $2150 \mathrm{Ft}$. Five questions allow a reasonable approximation to the indifference point, so we know how much we have to offer so that the participant is willing to wait 2 weeks to receive the payment. ${ }^{6}$ Suppose that a participant in task 1 (today vs. 2 weeks) in the last question chooses to receive $1730 \mathrm{Ft}$ in 2 weeks instead of $1000 \mathrm{Ft}$ today. Then (by the construction of the payoffs) we know that her indifference point is between $1730 \mathrm{Ft}$ and the closest lower amount (1650 Ft). For practical reasons, in this case, we consider that her indifference point is 1650 , so she needs a $650 \mathrm{Ft}$ compensation for waiting 2 weeks to receive the payment. ${ }^{7}$ If the same participant in task

\footnotetext{
${ }^{6}$ In Appendix B we represent graphically the map of the five choices that participants may have faced during this task. ${ }^{7} \mathrm{We}$ chose to proxy time preferences by the lower bound because if a participant is very impatient and always chooses the immediate $1000 \mathrm{Ft}$, then we know that her indifference point is above $2150 \mathrm{Ft}$, but we do not know how much above it. Therefore, considering the lower bound allows us to be consistent, but admittedly we underestimate somewhat the indifference point. Choosing the midpoint between bounds or the upper bound would not change our findings qualitatively.
} 
6 ( 4 weeks vs. 6 weeks) has the same indifference point, then she is time consistent, while a lower indifference point reveals that she is present-biased.

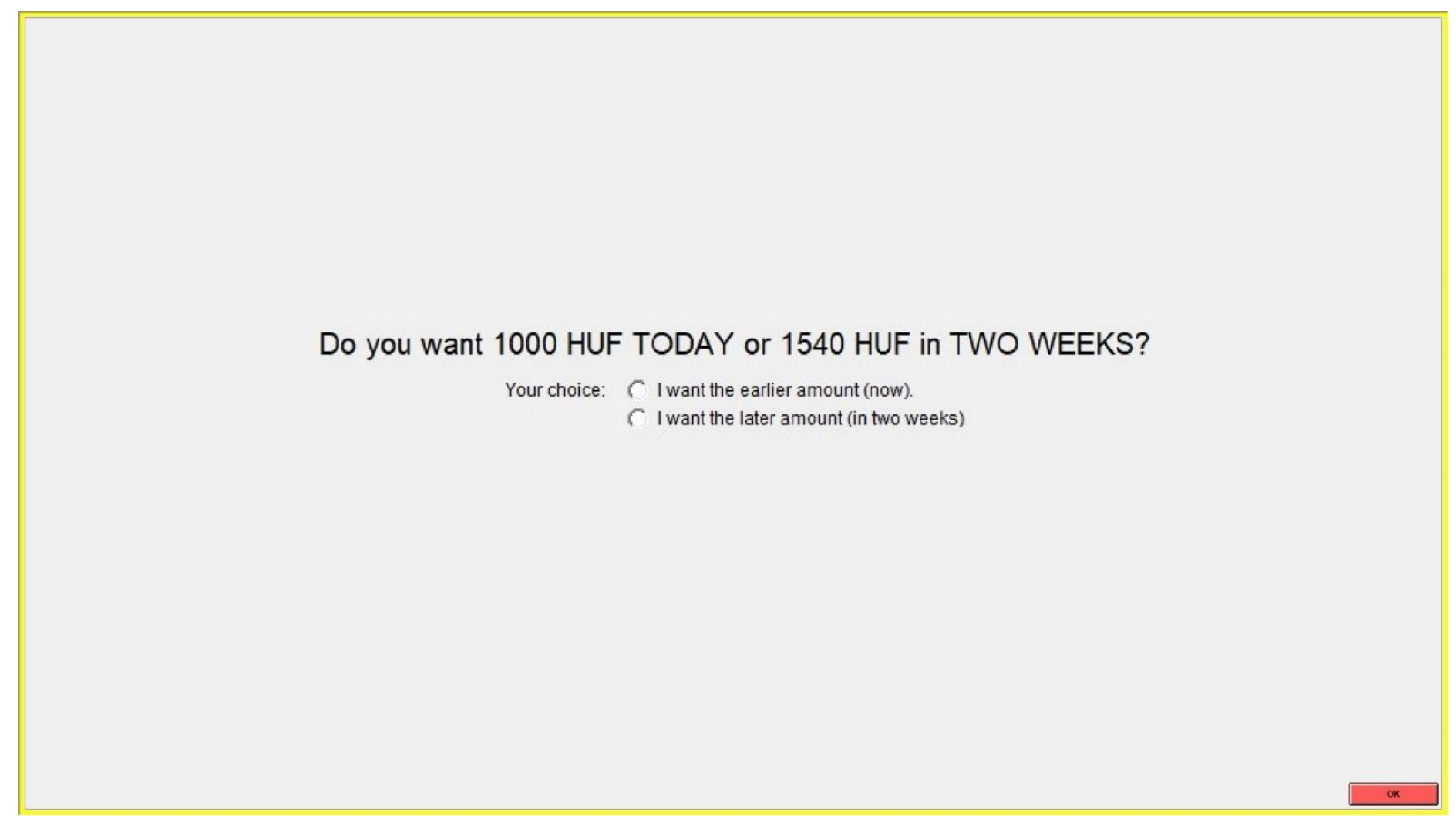

Figure 4. Screenshot from the first time preference task (now vs. 2 weeks)

There was also a $6^{\text {th }}$ choice in both time preference tasks to check the rationality and / or thoughtfulness of the participant. In this choice, the later amount either was very high (3000 Ft, which is triple the amount of the immediate payment) or lower than the earlier amount (900 Ft). If a participant chooses always the earlier $1000 \mathrm{Ft}$ instead of the later, but larger amounts, including $3000 \mathrm{Ft} 2$ weeks later, then it implies an extraordinarily high discounting of the future, which we considered an outlier. Choosing a later $900 \mathrm{Ft}$ instead of an earlier $1000 \mathrm{Ft}$ indicates negative discounting which seems to be extreme. Hence, with these control questions, we can identify participants who have very extreme time preferences or do not take the experiment seriously.

We explained to participants that if this task is chosen for payment, then one of the first 5 decisions would be picked randomly by the computer and their choice in that decision would be implemented. For example, if a student chooses $1540 \mathrm{Ft}$ in two weeks instead of $1000 \mathrm{Ft}$ today, then she would receive the $1540 \mathrm{Ft}$ in two weeks from the school administration as we explained above. 
The time preference tasks measure the amount of money to be received two weeks later that makes a participant indifferent to receive $1000 \mathrm{Ft}$ earlier. We will call these amounts Indifference amount now (based on choices between amounts now or in 2 weeks) and Indifference amount 4 weeks (based on choices between amounts in 4 weeks or in 6 weeks), and we will report the averages later in the paper. Larger indifference amounts indicate less patience.

\subsection{Risk preferences (task 4)}

Risk preferences indicate how an individual approaches a choice that has an uncertain outcome. Therefore, the tests to measure risk preferences involve some situation with uncertainty. Many of these tests include gambles (e.g. Eckel and Grossman 2002, Gneezy and Potters 1997, Holt and Laury 2002) that may seem strange to our student pool as evidenced by our experience in the Pilot high school, so we decided to use the bomb risk elicitation task by Crosetto and Filippin (2013). In this task, the participants are presented with the following short story. There is a store with 100 numbered boxes, one of which contains a bomb. The bomb can be in any of the boxes with the same probability. Participants have to decide how many boxes they want to collect, but the boxes can only be obtained in the order of their numbering. Earnings increase with the number of boxes collected that do not contain the bomb, but participants earn zero if the bomb is in one of their boxes. The number of boxes participants are willing to collect is a proxy for risk preferences. ${ }^{8}$

\footnotetext{
${ }^{8}$ Crosetto and Filippin (2016) compare four risk elicitation methods that are widely used in experimental economics, among them the bomb risk elicitation method and find that it is a valid measure of risk preferences.
} 


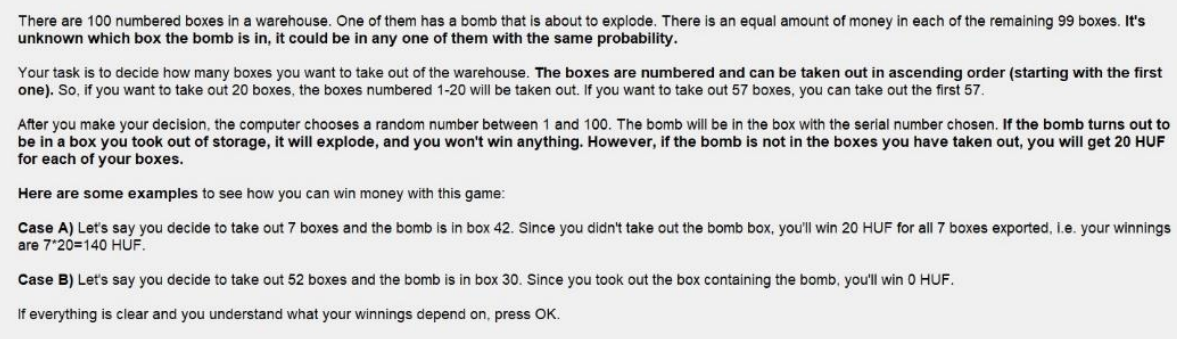

If everything is clear and you understand what your winnings depend on, press $\mathrm{OK}$.

\section{Figure 5. Screenshot of the risk preference task}

Participants knew that if this task was selected for payment, the computer would choose a random number between 0 and 100 indicating the box that contains the bomb. If the number of boxes that the participant decided to collect was below that number, then she would earn $20 \mathrm{Ft}$ for each box. Otherwise, her earning would be zero. We will report the average of boxes that participants decided to collect (Risk-taking: \# of boxes), larger numbers indicating more risk tolerance.

Choosing 100 boxes is equivalent to a sure explosion and zero earnings. We set the risktaking measure to missing if the student took 100 boxes.

\subsection{Social preferences}

Social preferences have many aspects. In our experiment, we focused on three: generosity, cooperativeness and trust.

\subsubsection{Generosity (task 2 and 3)}

We measured generosity (or altruism) with the dictator game. There were two dictator games. In the first one (task 2) we endowed all participants with $2000 \mathrm{Ft}$ that they could split 
between themselves and somebody else in the room, that is one of the classmates. We explained to participants that if at the end of the experiment this task was payoff-relevant, then we would pair the participants randomly. In each pair, the computer would randomly select one of the participants whose decision would be implemented. In task 3, we repeated this game, but this time the co-player was not somebody from the room, but a random schoolmate. This task was hypothetical.

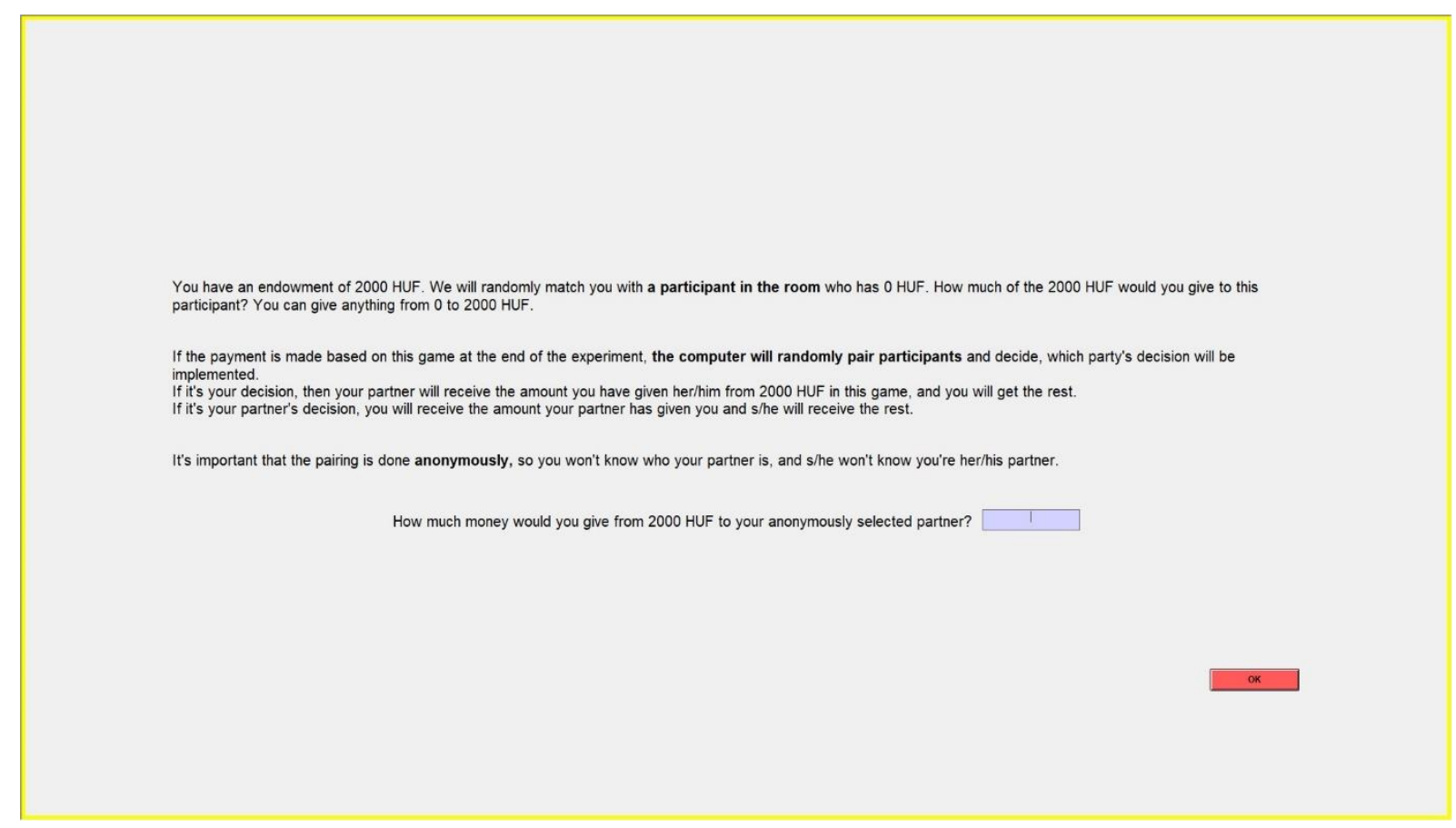

Figure 6. Screenshot of the dictator game

We will report the sum given to the classmate (Giving to classmate) and to the schoolmate (Giving to schoolmate), larger sums denoting more generosity.

\subsubsection{Cooperativeness (task 5)}

The second aspect of social preferences that we measured was how cooperative our participants were. We used the workhorse test of cooperation, the public goods game (task 5). However, instead of forming groups of 4 as is usual in most experiments with the public goods game, we applied a two-person variant. That is, we paired each participant randomly with somebody else from the room. Both of them were endowed with $1000 \mathrm{Ft}$, and they had to decide how much of the endowment to contribute to a common account, without knowing the contribution 
of the other participant. The amount that they did not contribute to the common project was theirs. From the common project, each of the two participants received $75 \%$ of the total contributions, independently of the individual contribution. Our measure of cooperativeness is the contribution to the common project: the more a participant contributes, the more cooperative she is.

To make the decision easier, on the decision screen, below the description of the task, participants had two sliders, both of them going from 0 to 1000 , the first corresponding to their contribution and the second corresponding to their co-player's contribution. By using the sliders, they could see the payoff consequences of different contribution combinations (see the decision screen in Figure 7).

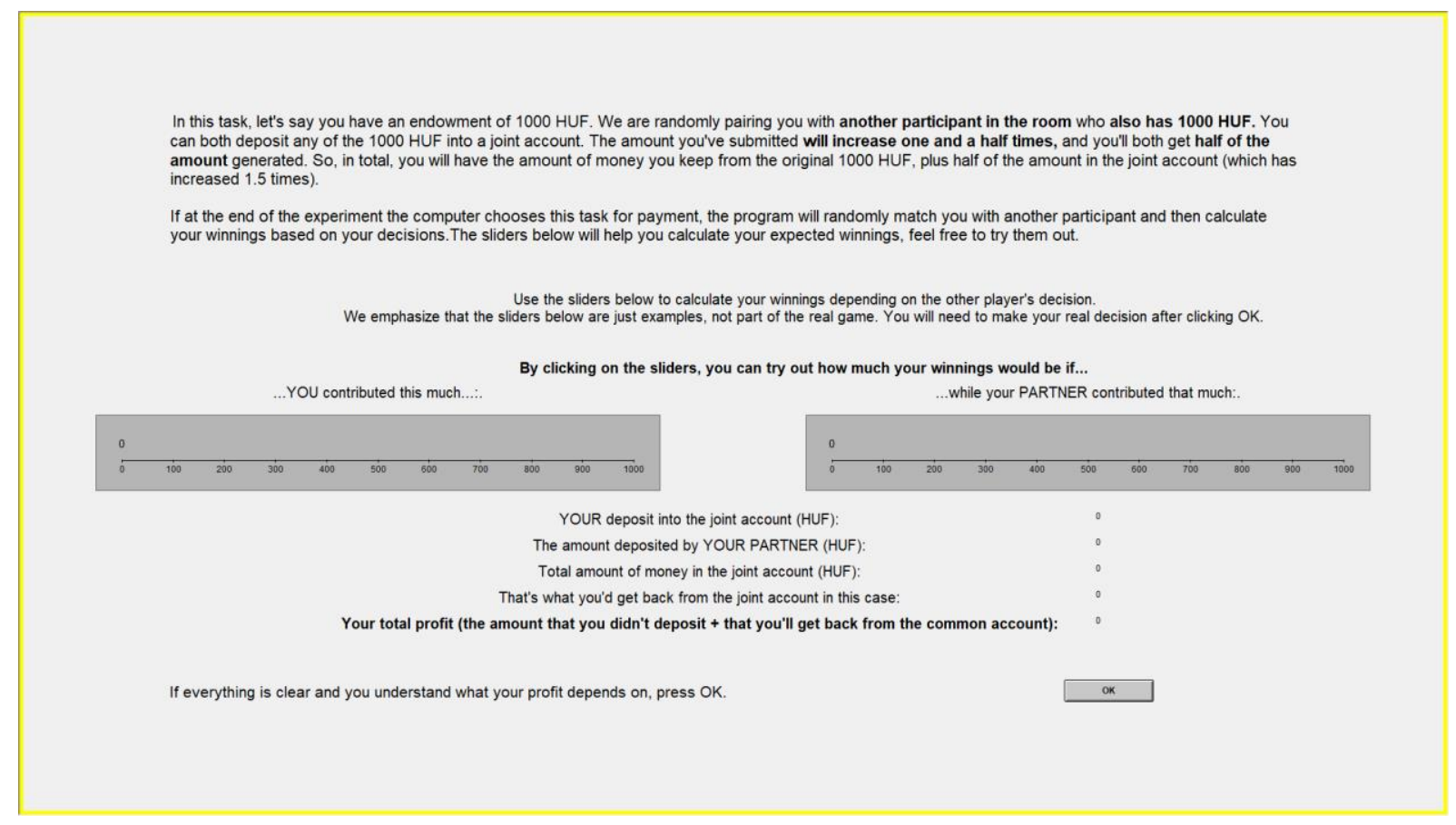

Figure 7: Screenshot from the cooperativeness task (public good game)

We will report the contribution to the common project (Cooperation: contribution), larger values implying higher levels of cooperativeness.

\subsubsection{Trust (task 7)}

We used the trust game (also known as investment game by Berg et al. 1995) to measure trust and trustworthiness of the participants. The game had two steps. In step 1, each participant played the role of the sender. They started with an endowment of $1000 \mathrm{Ft}$, and they decided how 
much to send to a randomly selected co-player in the room. The sum that they chose to send is a measure of trust. We told explicitly that the sum would be rounded to the nearest 100 . In step 2, the sent amount tripled. Here everybody assumed the role of the receiver and they had to state how much they would send back of the $3 * X$ if the sender had sent them $X(X=\{0,100,200, \ldots 1000\})$ Ft. Thus, we have answers to all contingencies, and this profile of responses provides a proxy of trustworthiness.

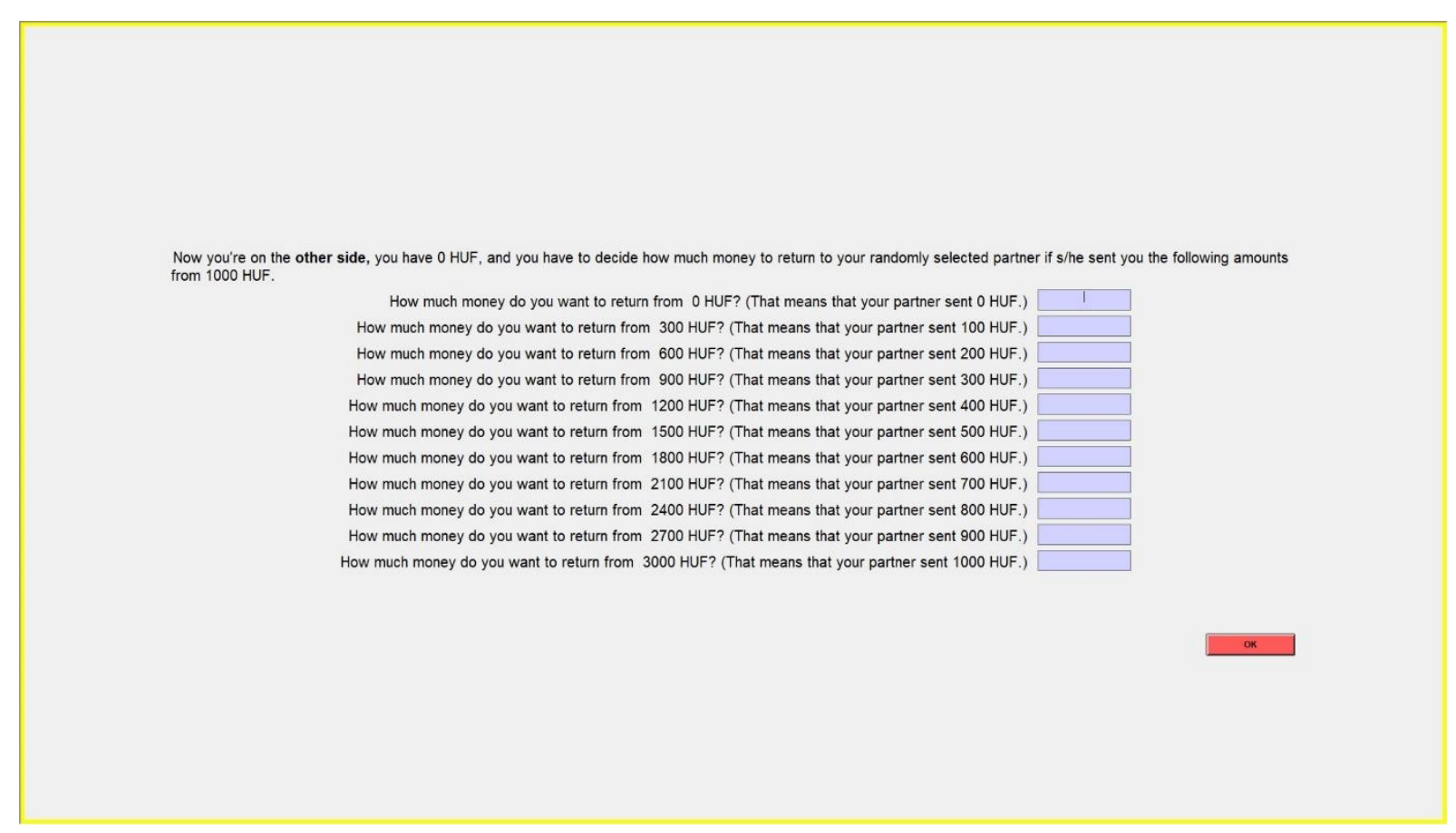

Figure 8. Screenshot from the second part of the trust game

We explained to the participants that if this task were chosen for payment, then the computer would form random pairs in the room and one player in each pair would be randomly chosen as sender and the other as a receiver and their corresponding choices would determine the payment.

We will report the sum that the participants sent (Trust: sum sent) and also the average percentage of the received sum that the participant returned (Trust: \% returned). Higher values indicate more trusting/trustworthy participants. 


\subsection{Competitiveness (task 8)}

In the last task of the experiment, we used the Niederle and Vesterlund (2007) setup to measure competitiveness. ${ }^{9}$ The only change that we made was to use a different real-effort task. Instead of adding up numbers, participants had to count zeros and ones in $5 \times 5$ matrices (for instance, in Abeler et al. 2011). Figure 4 shows a screenshot of the counting exercise. In each stage of the game, they had 1 minute to carry out the task.

The game started with the piece-rate stage in which participants were paid based on the number of correctly solved matrices, each paying $100 \mathrm{Ft}$. In stage 2, participants were evaluated as if they participated in a tournament, only the best $25 \%$ of the participants in the room earning money for the task. ${ }^{10}$ However, their earnings were 4 times as high per matrix solved as in stage 1. In stage 3, participants could choose if they wanted to get paid according to piece-rate or tournament, their choice indicating if they were competitive or not. After stage 3, we asked participants how they ranked themselves (being in the $1^{\text {st }} / 2^{\text {nd }} / 3^{\text {rd }} / 4^{\text {th }}$ quartile) based on their performance in stage 1 (piece rate) and stage 2 (tournament). These beliefs were elicited in an incentivized way as those who guessed correctly received $300 \mathrm{Ft}$ (if this task was chosen for payment).

At the end of the experiment, if the computer chose this task for payment, the computer picked one of the stages randomly and participants were paid according to their performance in that stage.

In our descriptive tables, we will report the share of competitive participants (Competitive).

\footnotetext{
${ }^{9}$ Lise Vesterlund was very kind to share with us their $\mathrm{z}$-tree code for which we are grateful.

${ }^{10}$ In case of tie, the computer randomly decided who got into the $25 \%$ to be paid.
} 


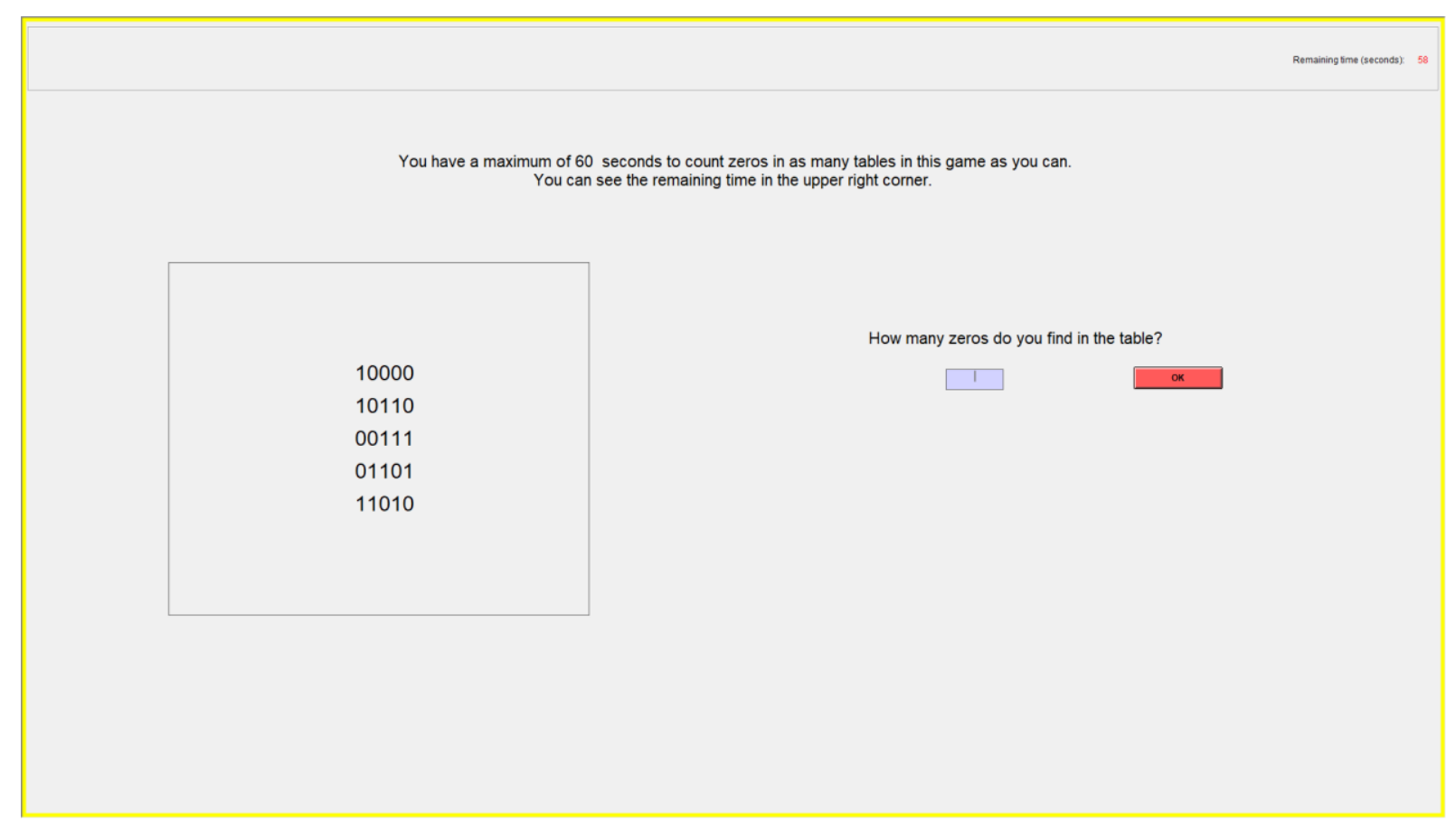

Figure 9: The real-effort task in the competitiveness task: counting zeros and ones

\section{Descriptive statistics}

The full sample consists of 1276 students from $8^{\text {th }}$ to $12^{\text {th }}$ grades $\left(8^{\text {th }}\right.$ grade: 41 students; $9^{\text {th }}$ grade: 418 students; $10^{\text {th }}$ grade: 385 students; $11^{\text {th }}$ grade: 336 students; $12^{\text {th }}$ grade: 96 students). 56 $\%$ of all participants were female.

We gained all student-level information - asides the economic preferences - from the National Assessment of Basic Competencies individual database. Gender and age data are missing only for a very few cases, but for $11 \%$ of the cases, socioeconomic status values are missing as these were self-reported in the NABC questionnaire.

As risk and competition preferences were measured differently in the Pilot school, descriptive statistics are shown without the pilot data. ${ }^{11}$ Table 2 shows the descriptive statistics of all raw preference measures that we have collected. We did not use the time preference measures of those students who gave an extreme or thoughtless answer to our control question (see section

\footnotetext{
${ }^{11}$ We report the descriptive statistics of the preferences measured in the Pilot school in section 3.1.
} 
2.2). We also did not use the risk-taking measures of those who chose to take 100 boxes out of the 100.

Students earned around 1000 HUF on average with a standard deviation of around 800 HUF (note that depending on the type of the game that was chosen for payment and the decisions of the students, the final profit varied between 0 and $6400 \mathrm{HUF})$.

\begin{tabular}{llcccc}
\hline Variable & $\mathrm{N}$ & Mean & SD & Min & Max \\
\hline \hline Female & 1036 & 0.56 & 0.50 & 0.00 & 1.00 \\
Age & 1035 & 16.93 & 1.14 & 14.00 & 21.00 \\
School grade & 1108 & 10.11 & 0.95 & 9.00 & 12.00 \\
Final profit & 1108 & 1038.99 & 831.70 & 0.00 & 6400.00 \\
Indifference amount now & 1077 & 1410.58 & 406.86 & 1030.00 & 3000.00 \\
Indifference amount 4 weeks & 1089 & 1414.15 & 344.87 & 1030.00 & 3000.00 \\
Risk: \# of boxes & 1100 & 33.62 & 18.52 & 1.00 & 99.00 \\
Risk, female & 578 & 30.94 & 18.25 & 1.00 & 99.00 \\
Risk, male & 450 & 37.38 & 18.64 & 1.00 & 99.00 \\
Giving to classmate & 1108 & 783.66 & 370.18 & 0.00 & 2000.00 \\
Giving to schoolmate & 1108 & 554.69 & 412.22 & 0.00 & 2000.00 \\
Cooperation: contribution & 1108 & 605.13 & 275.12 & 0.00 & 1000.00 \\
Trust: sum sent & 1108 & 551.81 & 253.69 & 0.00 & 1000.00 \\
Trust: $\%$ returned & 1108 & 38.82 & 16.45 & 0.00 & 100.00 \\
Competitive & 1108 & 0.61 & 0.49 & 0.00 & 1.00 \\
Competitive, female & 583 & 0.56 & 0.50 & 0.00 & 1.00 \\
Competitive, male & 453 & 0.66 & 0.47 & 0.00 & 1.00
\end{tabular}

Table 2. Descriptive statistics without the pilot data

Table 2 also reveals that students required approximately 400 extra Ft for having to wait two weeks to receive their payments, both when the choice was now vs 2 weeks and 4 vs 6 weeks. In the task measuring risk preferences, students collected on average 34 boxes which is somewhat lower than the literature reports (see Crosetto and Filippin 2013). Male participants collected more boxes than females which is an indication of higher risk tolerance, an often found gender difference in preferences (e.g. Croson and Gneezy 2009, or Bertrand 2011). Students were more generous toward their classmates than toward their schoolmates (who received about $28 \%$ of the endowment), giving more than $200 \mathrm{Ft}$ (10\% of their endowment) more to them. Participants contributed on average $60 \%$ of their endowment to the common project in the task measuring cooperation, which corresponds to the higher end of the findings in the literature (see Chaudhuri 2011). Similarly, the $55 \%$ that participants sent in the trust game is somewhat higher than the $50 \%$ observed in the literature (see Johnson and Mislin 2011). Being more cooperative and trusting is 
not surprising as in our experiment participant played with their classmates and not with strangers.

In line with the literature, we also find that males are more competitive than females (e.g. Niederle and Vesterlund 2011). Overall, the main descriptive statistics are in line with those found in the literature.

Table 3 shows the average preference measures by school. In some tasks, most of the schools exhibit similar average behaviour (e.g. sum returned in the trust game), but there are also big differences in other dimensions. For instance, in school MK students on average are much more impatient than their peers in school PB as they require more than $20 \%$ more money for having to wait two weeks (see row Indifference amount now). ${ }^{12}$

\begin{tabular}{|c|c|c|c|c|c|c|c|c|c|c|c|}
\hline School code & Pilot & FB & $\mathrm{KB}$ & KB2 & KK & KSZ & MK & NE & PB & SZB & $\begin{array}{r}\text { Means } \\
\text { without Pilot } \\
\end{array}$ \\
\hline Subject & 167 & 253 & 149 & 65 & 166 & 105 & 98 & 103 & 99 & 70 & \\
\hline Female & 0.53 & 0.39 & 0.65 & 0.90 & 0.66 & 0.66 & 0.55 & 0.56 & 0.56 & 0.41 & 0.56 \\
\hline Age & 16.42 & 16.38 & 17.83 & 15.98 & 16.48 & 19.30 & 16.74 & 17.44 & 16.45 & 17.32 & 16.93 \\
\hline Indifference amount now & 1352.50 & 1340.29 & 1451.22 & 1506.45 & 1380.43 & 1366.83 & 1569.57 & 1485.05 & 1297.081 & 1459.41 & 1410.58 \\
\hline Indifference amount 4 weeks & 1315.94 & 1307.76 & 1400.75 & 1538.44 & 1479.26 & 1443.24 & 1505.81 & 1447.50 & 1353.671 & 1428.84 & 1414.15 \\
\hline Risk-taking & 47.38 & 41.07 & 33.68 & 26.40 & 29.70 & 31.74 & 30.14 & 35.69 & 32.20 & 29.38 & 33.62 \\
\hline Risk, female & 51.20 & 39.07 & 32.05 & 26.91 & 27.06 & 29.73 & 28.35 & 34.57 & 28.49 & 27.07 & 30.94 \\
\hline Risk, male & 43.16 & 42.35 & 36.39 & 27.50 & 34.91 & 38.00 & 32.34 & 36.76 & 37.21 & 31.10 & 37.38 \\
\hline Giving to classmate & 892.76 & 705.51 & 862.68 & 851.54 & 808.76 & 869.10 & 852.76 & 654.61 & 735.36 & 808.64 & 783.66 \\
\hline Giving to schoolmate & 649.72 & 493.11 & 629.60 & 610.77 & 575.87 & 630.24 & 630.78 & 458.20 & 489.05 & 530.43 & 554.69 \\
\hline Cooperation: contribution & 630.95 & 660.98 & 626.85 & 510.29 & 573.86 & 628.30 & 603.63 & 587.73 & 595.18 & 526.29 & 605.13 \\
\hline Trust: sum sent & 634.73 & 618.18 & 573.15 & 478.46 & 504.82 & 544.76 & 528.57 & 549.51 & 546.46 & 500.00 & 551.81 \\
\hline Trust: \% returned & 42.00 & 36.61 & 42.01 & 35.52 & 37.84 & 40.12 & 42.34 & 37.25 & 37.60 & 42.50 & 38.82 \\
\hline Competitive & 0.67 & 0.55 & 0.64 & 0.52 & 0.61 & 0.69 & 0.61 & 0.59 & 0.61 & 0.76 & 0.61 \\
\hline Competitive, female & 0.65 & 0.50 & 0.59 & 0.53 & 0.53 & 0.64 & 0.57 & 0.60 & 0.52 & 0.79 & 0.56 \\
\hline Competitive, male & 0.70 & 0.56 & 0.75 & 0.33 & 0.79 & 0.88 & 0.66 & 0.58 & 0.69 & 0.73 & 0.66 \\
\hline
\end{tabular}

Note: Risk-taking means gamble games with staircase method in the Pilot school, bomb risk elicitation task in all other schools

Table 3. Raw averages by school

The aggregate school-level data suggest that there is considerable heterogeneity between schools in the preferences that we measured. ${ }^{13}$ Table 4 shows the $\mathrm{z}$-standardized scores of all preferences measures (with 0 mean and 1 standard deviation). As we will show later, there is also considerable heterogeneity in preferences within schools.

\footnotetext{
${ }^{12}$ Note also that on the other hand students on average are more generous in school MK than in school PB.

${ }^{13}$ The high values in the risk-taking task in the Pilot school may be due to the fact that there we used a different task. We converted the measure used there so that the numbers are comparable and we represent them for sake of completeness.
} 


\begin{tabular}{|c|c|c|c|c|c|c|c|c|c|c|}
\hline School code & Pilot & FB & KB & $\mathrm{KB} 2$ & KK & KSZ & MK & $\mathrm{NE}$ & $\mathrm{PB}$ & SZB \\
\hline Indifference amount now & -0.13 & -0.16 & 0.12 & 0.26 & -0.06 & -0.09 & 0.42 & 0.21 & -0.27 & 0.14 \\
\hline Indifference amount 4 weeks & -0.25 & -0.28 & 0.00 & 0.41 & 0.23 & 0.12 & 0.31 & 0.14 & -0.14 & 0.08 \\
\hline Risk-taking & 0.63 & 0.30 & -0.09 & -0.47 & -0.30 & -0.19 & -0.28 & 0.01 & -0.17 & -0.32 \\
\hline Risk, female & 0.92 & 0.29 & -0.08 & -0.34 & -0.33 & -0.20 & -0.27 & 0.05 & -0.26 & -0.33 \\
\hline Risk, male & 0.27 & 0.22 & -0.10 & -0.57 & -0.18 & -0.01 & -0.31 & -0.08 & -0.05 & -0.38 \\
\hline Giving to classmate & 0.26 & -0.25 & 0.18 & 0.15 & 0.03 & 0.19 & 0.15 & -0.39 & -0.17 & 0.03 \\
\hline Giving to schoolmate & 0.20 & -0.18 & 0.15 & 0.11 & 0.02 & 0.15 & 0.15 & -0.26 & -0.19 & -0.09 \\
\hline Cooperation: contribution & 0.08 & 0.19 & 0.07 & -0.35 & -0.12 & 0.07 & -0.02 & -0.07 & -0.05 & -0.30 \\
\hline Trust: sum sent & 0.28 & 0.22 & 0.04 & -0.33 & -0.23 & -0.07 & -0.13 & -0.05 & -0.06 & -0.25 \\
\hline Trust: \% returned & 0.17 & -0.16 & 0.17 & -0.23 & -0.09 & 0.05 & 0.19 & -0.12 & -0.10 & 0.20 \\
\hline
\end{tabular}

Note: Risk-taking means gamble games with staircase method in the Pilot school, bomb risk elicitation task in all other schools

Table 4. Z-standardized averages by school

Table 4 reports averages, but the whole distribution of preferences may provide interesting insights into the heterogeneity of preferences between schools as well. In Figures 10-17 we show boxplot graphs that illustrate how dispersed the observations are school by school. ${ }^{14}$

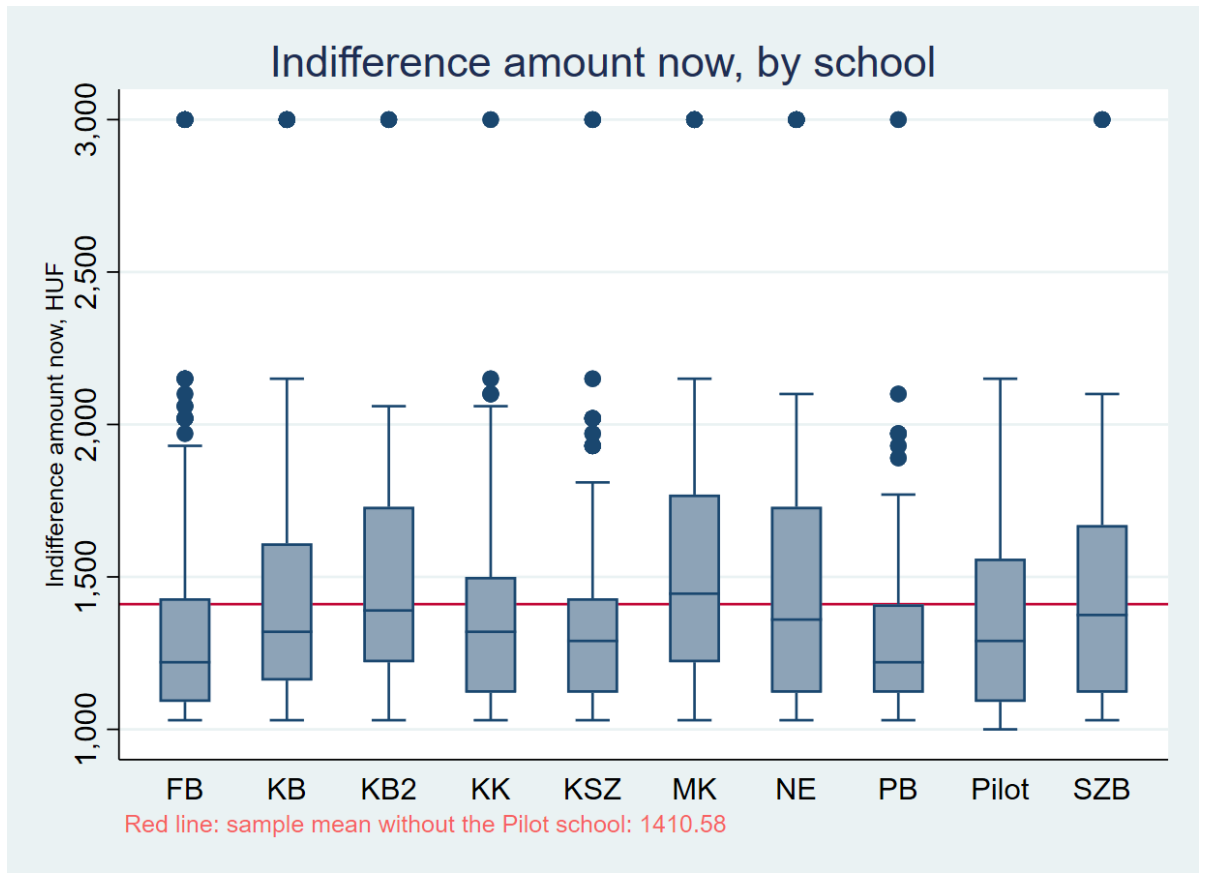

Figure 10. Heterogeneity of the preference measures - Indifference amount now

Figure 10 indicates that extra money needed to make a student indifferent between receiving the money now or in two weeks is much more dispersed in some schools than on others. For instance, in schools FB, KSZ and PB the indifference amounts are not only lower on average, but they are also more concentrated than in schools KB2, MK or NE. Figure 11 shows similar patterns for the other time preference task.

\footnotetext{
${ }^{14}$ The horizontal line within the box represents the median, while the bottom / top of the box indicates the 25th / 75 th percentile of the observations. The upper (lower) adjacent value is the 75 th (25th) percentile plus (minus) $3 / 2$ times the interquartile range.
} 


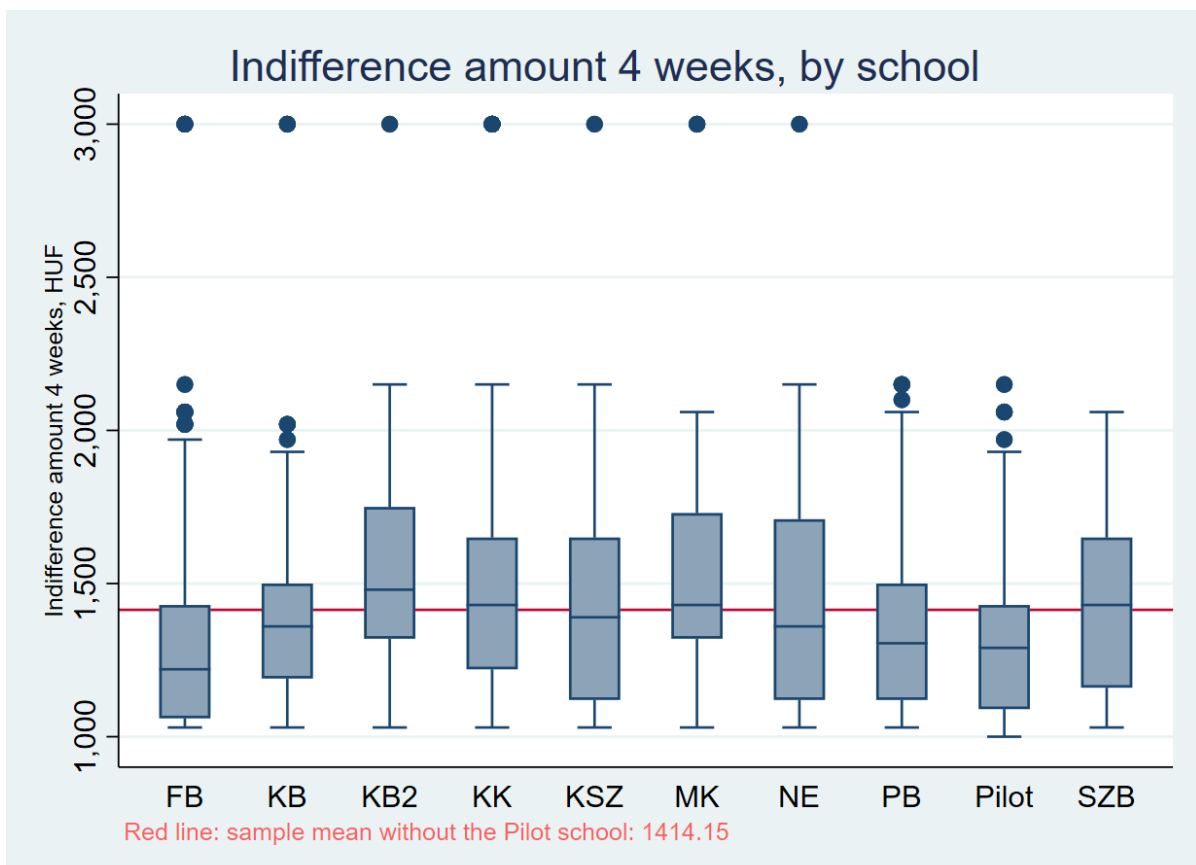

Figure 11. Heterogeneity of the preference measures - Indifference amount 4 weeks

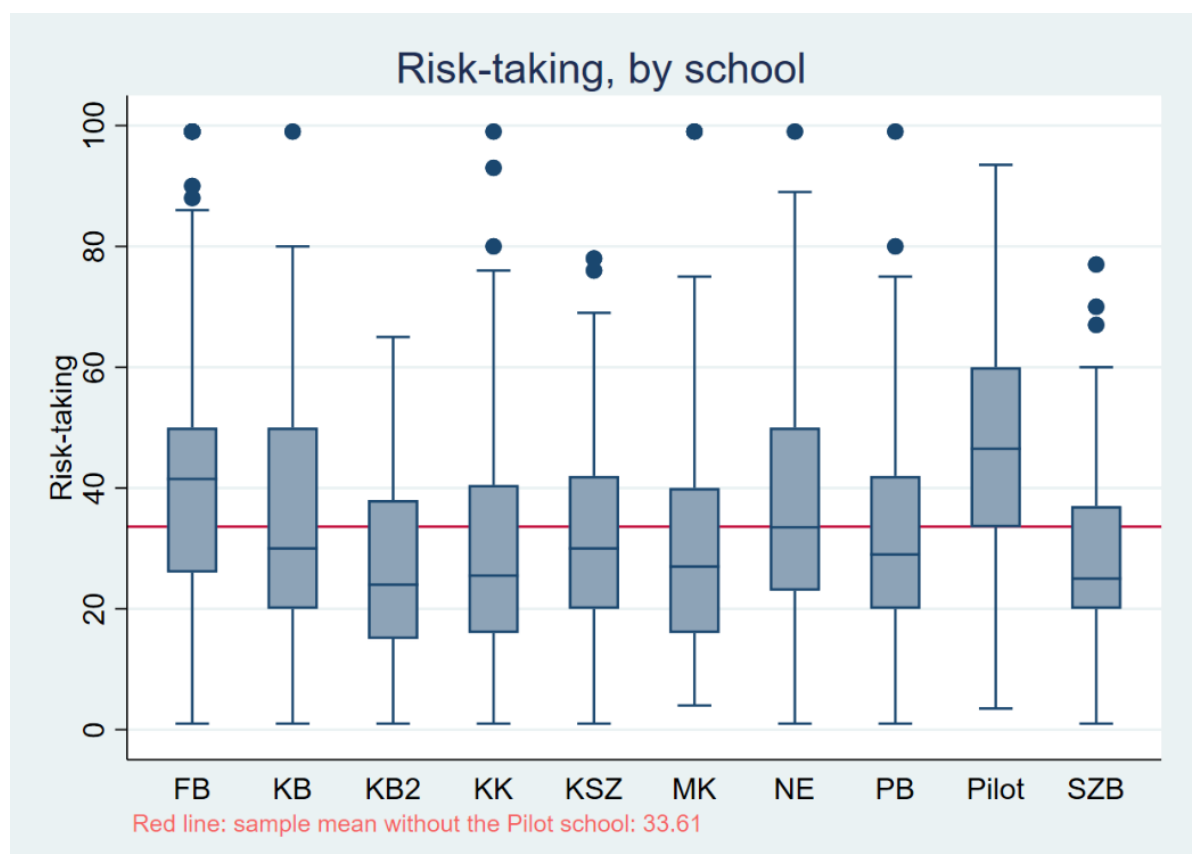

Note: Risk-taking means gamble games with staircase method in the Pilot school, bomb risk elicitation task in all other schools Figure 12. Heterogeneity of the preference measures - Risk-taking

Figure 12 reveals that even though the average number of boxes collected in the bomb risk elicitation task (our risk measure) differ considerably across schools, the distributions do not seem very different. 


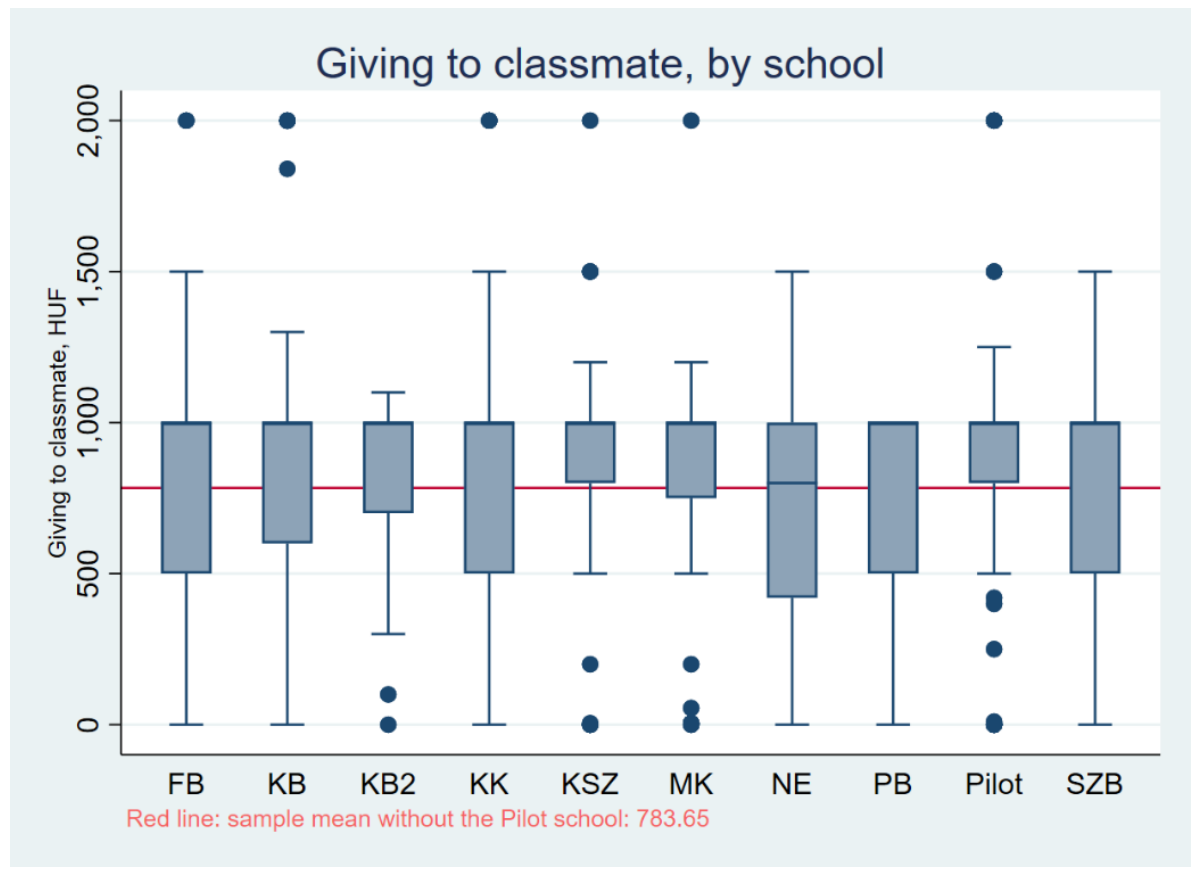

Figure 13. Heterogeneity of the preference measures - Giving to classmate

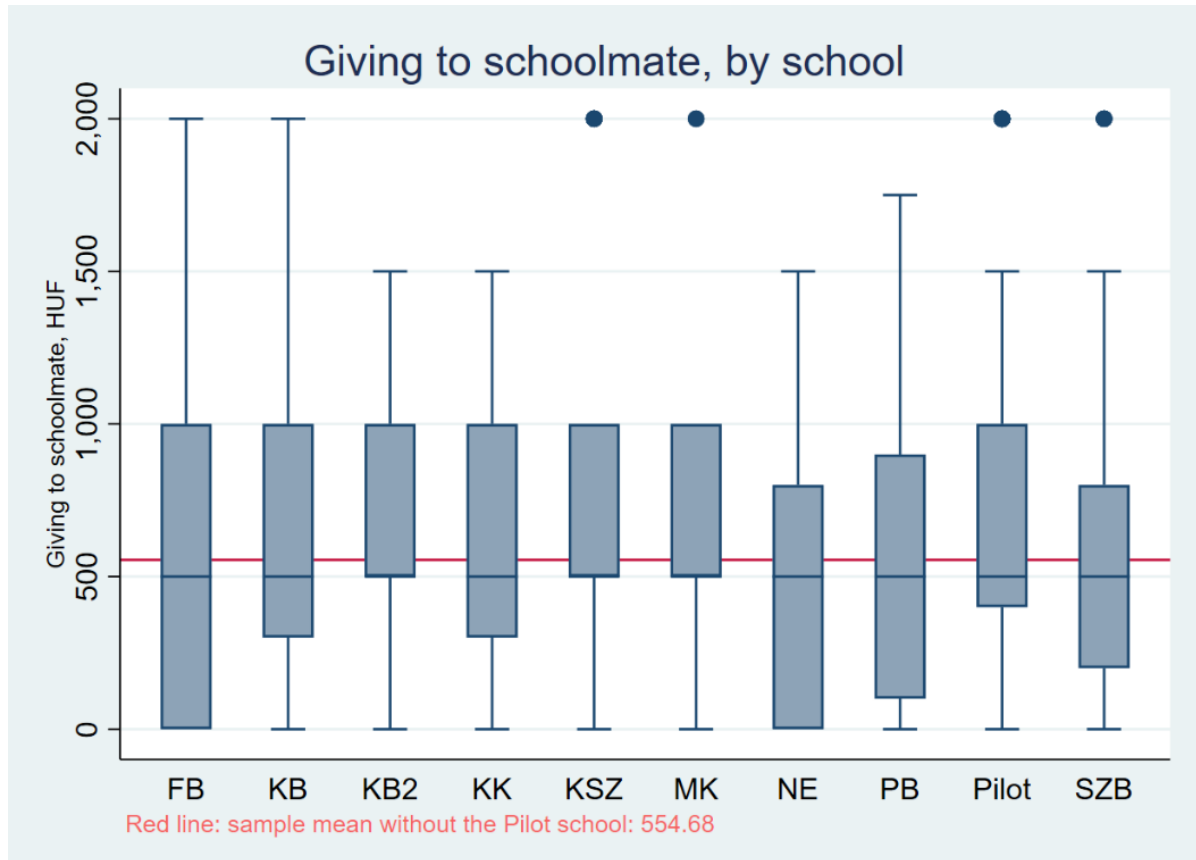

Figure 14. Heterogeneity of the preference measures - Giving to schoolmate

Figure 13 indicates that regarding Giving to classmate not only the average amounts differ across schools, but also the dispersion of the data. In schools KSZ, MK and Pilot students are not only more generous on average to their classmates, but in these schools, most of the students are similarly generous to each other. Figure 14 demonstrates that when it comes to giving to a random schoolmate, generosity declines, and it also becomes more dispersed. 


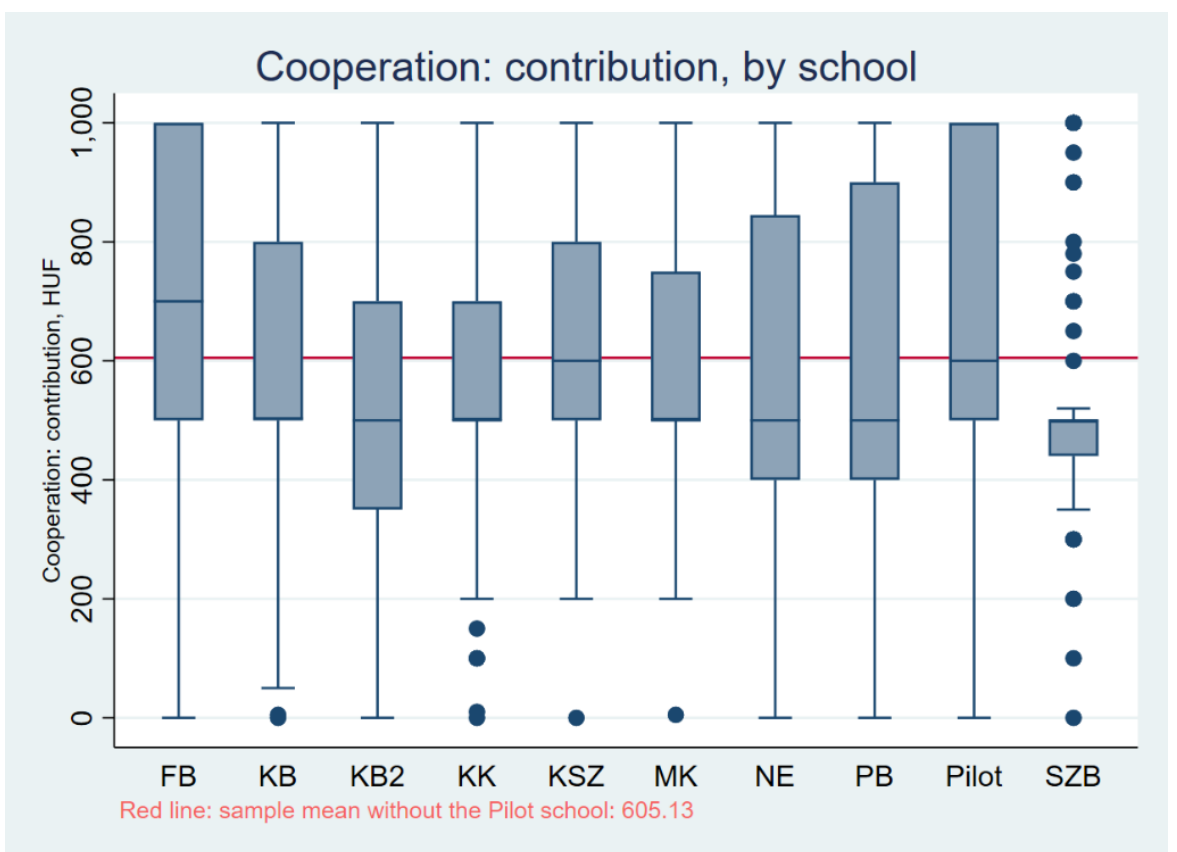

Figure 15. Heterogeneity of the preference measures - Cooperativeness

Figure 15 uncovers heterogeneity across schools in cooperativeness. In schools where the average contribution is low, the distribution tends to be less spread out than in schools with higher averages.

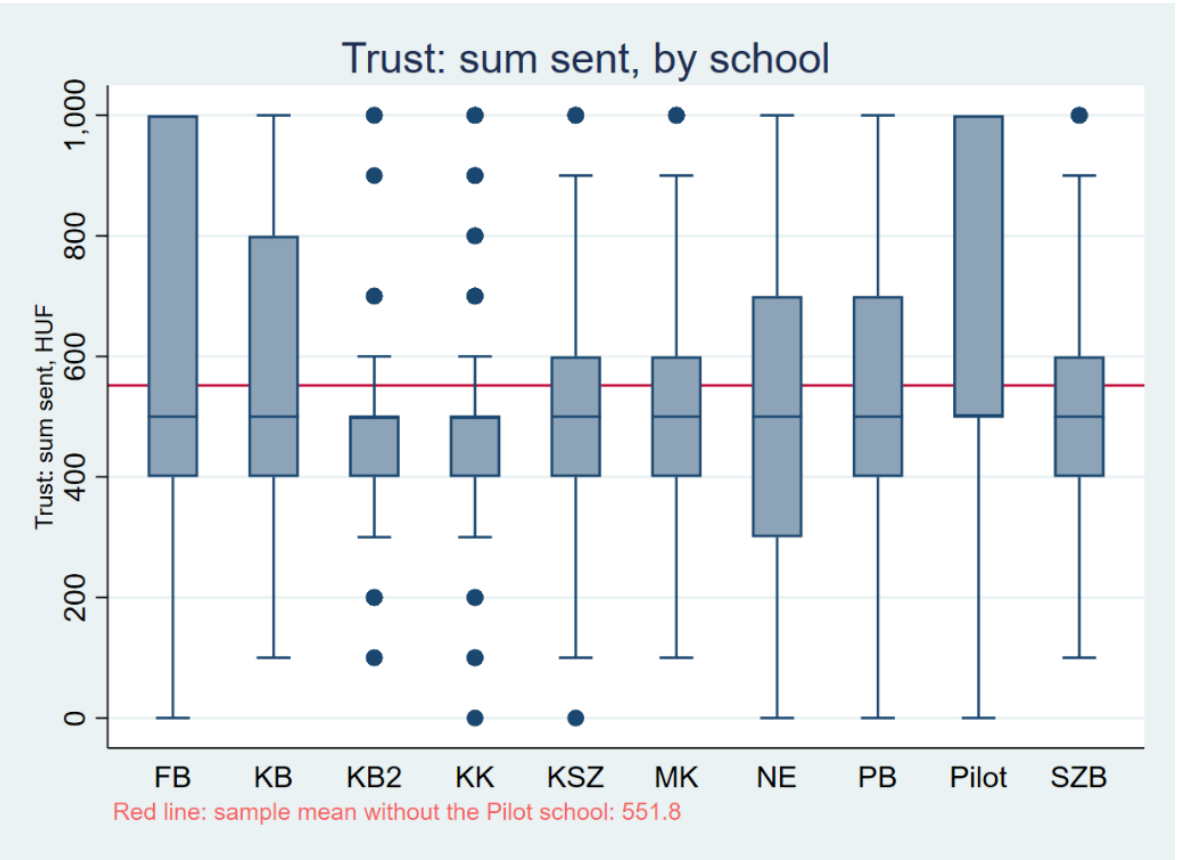

Figure 16. Heterogeneity of the preference measures - Trust: sum sent 
Heterogeneity is also present in trusting behaviour as exemplified by Figure 16. Averages do not differ much across schools, but clearly, the decisions are more dispersed in some schools than others.

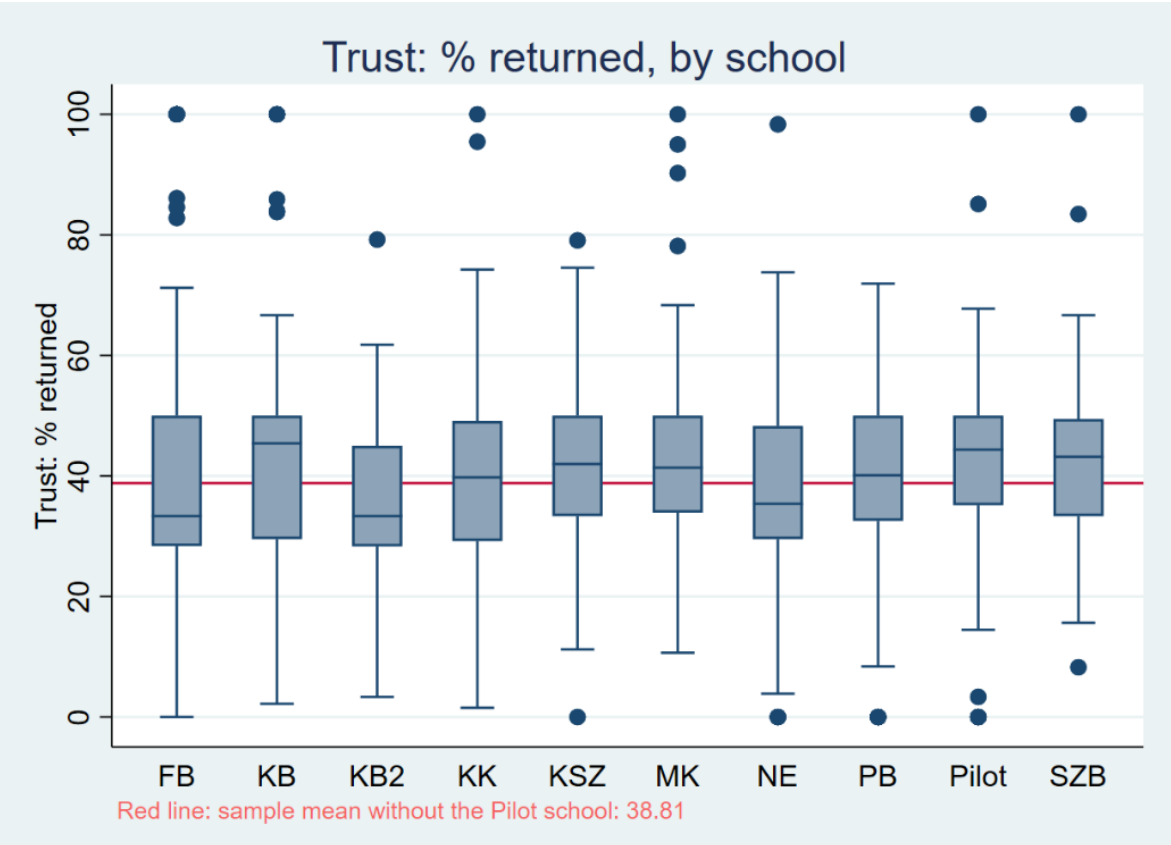

Figure 17. Heterogeneity of the preference measures - Trust: sum returned

Figure 17 shows that concerning the share of money returned to the sender, we do not see much heterogeneity across schools.

Although the previous figures suggest that there is some heterogeneity across schools, but it also shows that there is considerable overlap in behaviour across schools. In Appendix $\mathrm{C}$ we show probability density functions (both pooling all schools in one graph and separately) that expose the degree of similarity of behaviour across schools as it is hard to distinguish the probability density functions in many cases. These functions also illustrate the presence of focal points in many measures (e.g. giving or contribution 500 or $1000 \mathrm{Ft}-\mathrm{s})$.

\subsection{Pilot school}

First, we ran the pilot version of the experiment. 168 students from 18 school groups participated in the study. All groups were academic classes, and 53\% of the students were female. This school operates in Budapest. A unique feature of this school is that the school groups are 
rather small, comprising less than 20 students on average. Due to technical difficulties, zTree did not save the data properly at the end of session 2 (Group 2), and we were only able to recover the output partially. The final data loss did not affect the main variables presented in Table 5.

As reported in Table 5, most of the groups were more patient than the average of the full sample as they required less than 400 HUF for having to wait two weeks now or a month later. Regarding risk-taking, students were well above average, and in most groups, male students were more risk-averse than female students which is the opposite of what we observe in other schools. This might be due to the fact that in the Pilot school, we used a different (gambling) game for measuring risk aversion than in the other institutions. There is considerable heterogeneity in the degree of generosity, that is, in the amount of money that students would give to their classmates in different groups. However, this amount always exceeds the average sum they would give to a schoolmate. Competitiveness was also differently assessed in this school than in the others. Female students were more competitive in half of the groups. 


\begin{tabular}{|c|c|c|c|c|c|c|c|c|c|c|c|c|c|c|c|c|c|c|}
\hline $\begin{array}{l}\text { Group } \\
\end{array}$ & 1 & 2 & 3 & 4 & 5 & 6 & 7 & 8 & 9 & 10 & 11 & 12 & 13 & 14 & 15 & 16 & 17 & 18 \\
\hline Academic & $\bar{~} 1$ & $\bar{~} 1$ & $\overline{11}$ & 1 & 1 & 1 & 1 & 1 & 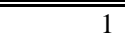 & 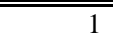 & 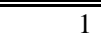 & $\bar{~} 1$ & 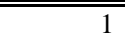 & 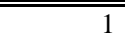 & 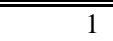 & $\bar{~} 1$ & 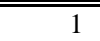 & $\overline{1}$ \\
\hline Grade & 9 & 9 & 9 & 9 & 9 & 9 & 9 & 11 & 11 & 11 & 11 & 8 & 8 & 8 & 8 & 8 & 11 & 11 \\
\hline ubject & 12 & 11 & 10 & 6 & 11 & 10 & 11 & 16 & 10 & 10 & 6 & 7 & 7 & 8 & 9 & 10 & 8 & \\
\hline r Payment & ictator & Trust game & $\begin{array}{r}\text { game good } \\
\text { game }\end{array}$ & Risk & $\begin{array}{r}\text { Time now } \\
\text { vs. } 2 \\
\text { weeks }\end{array}$ & $\begin{array}{r}\text { ompetitio } \\
n\end{array}$ & Risk & $\begin{array}{l}\text { Time } \\
\text { now vs. } \\
2 \text { weeks }\end{array}$ & $\begin{array}{r}\text { Time } 4 \\
\text { weeks vs. } \\
6 \text { weeks }\end{array}$ & Dictator & $\begin{array}{r}\text { Public } \\
\text { good } \\
\text { game }\end{array}$ & $\begin{array}{r}\text { Time } 4 \\
\text { weeks vs. } \\
6 \text { weeks }\end{array}$ & $\begin{array}{r}\text { Time } 4 \\
\text { weeks vs. } \\
6 \text { weeks }\end{array}$ & $\begin{array}{r}\text { Time } 4 \\
\text { weeks vs. } \\
6 \text { weeks }\end{array}$ & Dictator & ctator & Risk & \\
\hline Female & 0.40 & 0.38 & 0.50 & 0.17 & 0.64 & 0.70 & 0.60 & 0.53 & 0.60 & 0.70 & 0.17 & 0.43 & 0.71 & 0.25 & 0.33 & 0.70 & 0.75 & 0.80 \\
\hline ge & 50 & 63 & 15.70 & 16.00 & 15.55 & 15.90 & 15.80 & 18.93 & 18.80 & 18.90 & 19.17 & 14.43 & 15.00 & 14.63 & 14.89 & 14.50 & 17.88 & 17.60 \\
\hline hdiff. amount now & 386.00 & 1410.91 & 1288.89 & 1468.33 & 1433.64 & 1358.00 & 1343.64 & 1614.29 & 1256.00 & 1361.25 & 1271.67 & 1135.71 & 1310.00 & 1313.75 & 1197.78 & 1190.00 & 1237.14 & 1545.00 \\
\hline 4 weeks & 36.67 & 22.73 & 1371.00 & 1350.00 & 1331.82 & 1292.00 & 1433.64 & 1400.00 & 1325.00 & 1147.00 & 1390.00 & 1214.29 & 1196.67 & 1288.75 & 1274.44 & 1372.22 & 1258.75 & 1385.00 \\
\hline & .46 & & 60 & & .18 & 37.65 & & 55.13 & 46.61 & 55.90 & 42.17 & 41.93 & 46. & 51.19 & 37. & 53.72 & 53.75 & 47.75 \\
\hline Risk, $\mathrm{f}$ & 3.25 & .50 & 9.30 & 50 & 56.14 & 42.86 & 43.92 & 64.50 & 44.92 & 57.50 & 56.50 & 49.00 & 47.20 & 38.25 & 40.00 & 57.83 & 54.50 & 51.63 \\
\hline & & & & & 34.25 & 25.50 & & 39.93 & 50.00 & 52.17 & 39.30 & 36.63 & 40.00 & 55.50 & 35.58 & 45.50 & 51.50 & 33.50 \\
\hline & 041.67 & 1.73 & 0.00 & 533.33 & 0.91 & 930.00 & 850.00 & 889.19 & 880.00 & 751.00 & 915.83 & 935.71 & 1200.00 & 508.75 & 955 & 970.00 & 848.75 & 1041.67 \\
\hline & & & .00 & .67 & .18 & & 4.55 & 678.06 & 530.00 & 621.00 & 415 & 73. & & 446 & 688.89 & 660.00 & 485.00 & 791.67 \\
\hline & & & & & & & & 547.25 & & & & & & 450.00 & 822.22 & 680.00 & 668.75 & 600.00 \\
\hline Trust & 5.00 & 700.00 & 630.00 & 500.00 & 0.00 & 690.00 & 536.36 & 543.75 & 670.00 & 670.00 & 650.00 & 771.43 & 800.00 & 487.50 & 588.89 & 650.00 & 712.50 & 616.67 \\
\hline & & & & & & & & 44.69 & 37.24 & & 55.29 & 44.19 & 51.99 & 42.12 & 44.69 & 39.09 & 47.07 & 44.78 \\
\hline Com & 0.92 & 0.64 & 0.70 & 0.8 & 0.55 & 0.50 & 0.8 & 0.75 & 0.70 & 0.70 & 0.50 & 0.29 & 0.43 & 0.63 & 0.67 & 0.70 & 0.75 & 0.83 \\
\hline & 1.00 & 0.67 & 0.60 & & 0.43 & 0.57 & 0.67 & 0.88 & 0.50 & 0.57 & 1.00 & 0.33 & 0.20 & 1.00 & 0.67 & 0.71 & 0.83 & 0.75 \\
\hline Competitive, male & 1.00 & 0.60 & 0.80 & 0.80 & 0.75 & 0.33 & 1.00 & 0.71 & 1.00 & 1.00 & 0.40 & 0.25 & 1.00 & 0.50 & 0.67 & 0.67 & 0.50 & 1.00 \\
\hline
\end{tabular}

Table 5. Desriptive data from the Pilot school 


\subsection{School FB}

We ran our experiment at school FB twice, first in March 2019 and then exactly a year later in March 2020 (two weeks before the Covid-19 lockdown). The finalized version of the games was used both times. This was the only school where certain school groups repeated the experiment (see Group 1 and Group 4 in Table 6), which also means that there are 52 students out of the 253 in total in this school, who appear twice in our subsample from FB.

All groups were academic classes, and 39\% of the participants were female. This school operates in Budapest, and we used the computers provided by the institution.

There were no technical difficulties during the sessions. In the second year, every student participated in a psychological experiment attached to ours. That is, they had to play a short (5-10 minute) computer game measuring cognitive functions immediately before or after our experiment.

In school FB, students were, on average, more patient than the average of the sample. Most groups were overall present biased. Both male and female students were more risktolerant but less competitive than the average of the whole sample. Still, there is considerable heterogeneity between groups in this regard. Students in this school were less generous than the average, but for example Group 1 or 6 sent almost twice as much to their peers in both dictator games than Group 7. However, they were more cooperative and trusted their classmates more. Differences between different groups are also noteworthy in most of the tasks.

The most interesting finding here is the change in preferences in the groups that participated in the experiment twice. For example, in the first year, female students were more risk-averse in Group 1 and 4. A year later, these groups were more risk-tolerant on average (even when we look at the averages by gender), but female students became more risk-tolerant in both groups compared to their male classmates. In the competition game, gender differences in the willingness to compete remained the same a year later. 


\begin{tabular}{|c|c|c|c|c|c|c|c|c|c|c|}
\hline Group & 1 & 2 & 3 & 4 & 5 & 4 again & 6 & 1 again & 7 & 8 \\
\hline Academic & 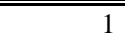 & 1 & 1 & 1 & 1 & 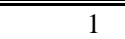 & 1 & 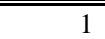 & 1 & 1 \\
\hline Grade & 9 & 10 & 10 & 9 & 9 & 10 & 9 & 10 & 10 & 10 \\
\hline Subject & 22 & 23 & 24 & 30 & 27 & 30 & 20 & 22 & 29 & 26 \\
\hline Game For Payment & $\begin{array}{r}\text { Time } 4 \\
\text { weeks vs. } \\
6 \text { weeks } \\
\end{array}$ & $\begin{array}{r}\text { Public } \\
\text { good } \\
\text { game }\end{array}$ & Competition & $\begin{array}{r}\text { Time now } \\
\text { vs. } 2 \\
\text { weeks } \\
\end{array}$ & Risk & $\begin{array}{l}\text { Trust } \\
\text { game g }\end{array}$ & $\begin{array}{r}\text { Public } \\
\text { ood game }\end{array}$ & $\begin{array}{r}\text { ime now } \\
\text { vs. } 2 \\
\text { weeks }\end{array}$ & Dictator & Competition \\
\hline Female & 0.43 & 0.52 & 0.46 & 0.25 & 0.08 & 0.20 & 0.60 & 0.50 & 0.38 & 0.60 \\
\hline Age & 15.67 & 16.87 & 16.75 & 15.64 & 15.88 & 16.73 & 15.70 & 16.68 & 16.76 & 16.92 \\
\hline Indiff. amount now & 1380.45 & 1415.45 & 1463.04 & 1219.66 & 1153.85 & 1158.97 & 1346.11 & 1502.73 & 1587.14 & 1250.00 \\
\hline Indiff. amount 4 weeks & 1419.55 & 1324.35 & 1260.83 & 1195.33 & 1250.38 & 1209.67 & 1325.79 & 1490.00 & 1439.29 & 1233.08 \\
\hline Risk: \# of boxes & 34.45 & 34.14 & 36.25 & 38.48 & 41.48 & 46.93 & 44.30 & 43.00 & 47.72 & 41.23 \\
\hline Risk, female & 32.00 & 30.09 & 31.82 & 30.00 & 44.50 & 51.50 & 50.42 & 48.82 & 38.27 & 37.53 \\
\hline Risk, male & 35.17 & 38.18 & 40.00 & 41.05 & 41.74 & 45.79 & 35.13 & 36.60 & 53.50 & 45.90 \\
\hline Giving to classmate & 918.18 & 710.57 & 791.67 & 673.63 & 667.33 & 541.67 & 914.00 & 738.14 & 489.83 & 759.62 \\
\hline Giving to schoolmate & 743.64 & 504.35 & 523.33 & 522.00 & 383.48 & 228.33 & 715.00 & 500.86 & 327.76 & 636.54 \\
\hline Cooperation: contrib. & 643.18 & 554.35 & 494.29 & 736.67 & 781.89 & 734.07 & 596.55 & 608.91 & 696.93 & 680.58 \\
\hline Trust: sum sent & 490.91 & 552.17 & 533.33 & 693.33 & 681.48 & 730.00 & 595.00 & 577.27 & 600.00 & 653.85 \\
\hline Trust: \% returned & 41.76 & 31.00 & 43.58 & 37.10 & 33.81 & 30.79 & 45.37 & 39.68 & 35.98 & 31.21 \\
\hline Competitive & 0.64 & 0.48 & 0.67 & 0.60 & 0.33 & 0.43 & 0.65 & 0.50 & 0.59 & 0.62 \\
\hline Competitive, female & 0.67 & 0.42 & 0.64 & 0.43 & 0.00 & 0.33 & 0.67 & 0.55 & 0.27 & 0.53 \\
\hline Competitive, male & 0.58 & 0.55 & 0.69 & 0.62 & 0.35 & 0.46 & 0.63 & 0.45 & 0.78 & 0.70 \\
\hline
\end{tabular}

Table 6. Descriptive data from school FB

\subsection{School KB}

This school also operates in Budapest. We measured the preferences of 149 students in 10 school groups, $65 \%$ of the participants were female.

$\mathrm{KB}$ is a bilingual school with students whose native language is not necessarily Hungarian. As our experiment was entirely in Hungarian, we paid 1000 HUF to two students who went to one of the participating classes but were excluded from the games due to the language barrier.

Using the computers of the school, we ran two sessions at the same time in two different classrooms.

On the school level, students in KB were less risk-tolerant but more competitive than the average, even by gender. Their earlier indifference point was a bit bigger than the sample's average, so they were present biased to some extent (on the group level this applies to 6 classes). Almost all groups were more generous than the average, and they were slightly more cooperative and trusted their classmates more. Heterogeneity across groups is large in many cases, for instance, in some groups classmates on average gave more than $200 \mathrm{Ft}-\mathrm{s}$ more to each other than in others. 


\begin{tabular}{|c|c|c|c|c|c|c|c|c|c|c|}
\hline Group & 1 & 2 & 3 & 4 & 5 & 6 & 7 & 8 & 9 & 10 \\
\hline Academic & 1 & 1 & 1 & 1 & 1 & 1 & 1 & 1 & 1 & $\overline{1}$ \\
\hline Grade & 9 & 11 & 9 & 11 & 11 & 11 & 10 & 9 & 10 & 9 \\
\hline Subject & 18 & 19 & 14 & 14 & 15 & 13 & 15 & 18 & 10 & 13 \\
\hline Game For Payment & Dictator & Dictatorgo & $\begin{array}{l}\text { Public } \\
\text { od game }\end{array}$ & Competition & Competition & $\begin{array}{l}\text { Trust } \\
\text { game }\end{array}$ & $\begin{array}{r}\text { Time } 4 \\
\text { weeks vs. } \\
6 \text { weeks } \\
\end{array}$ & $\begin{array}{r}\text { Time } 4 \\
\text { weeks vs. } \\
6 \text { weeks } \\
\end{array}$ & \multicolumn{2}{|c|}{$\begin{array}{l}\text { Trust } \\
\text { game Competition }\end{array}$} \\
\hline Female & 0.61 & 0.63 & 0.46 & 0.57 & 0.60 & 0.69 & 0.71 & 0.71 & 0.70 & 0.83 \\
\hline Age & 16.67 & 18.95 & 16.92 & 18.57 & 18.73 & 19.00 & 17.86 & 16.76 & 18.00 & 16.92 \\
\hline Indiff. amount now & 1583.53 & 1518.95 & 1499.29 & 1300.71 & 1443.33 & 1306.15 & 1390.67 & 1557.06 & 1341.00 & 1460.00 \\
\hline Indiff. amount 4 weeks & 1497.06 & 1314.21 & 1515.00 & 1302.14 & 1488.67 & 1199.23 & 1434.00 & 1480.00 & 1250.00 & 1458.46 \\
\hline Risk: \# of boxes & 29.78 & 36.53 & 27.86 & 36.64 & 34.93 & 34.92 & 27.67 & 37.83 & 44.20 & 28.38 \\
\hline Risk, female & 28.82 & 34.50 & 23.67 & 27.75 & 32.89 & 36.67 & 31.00 & 34.75 & 42.86 & 26.50 \\
\hline Risk, male & 31.29 & 40.00 & 29.71 & 48.50 & 38.00 & 31.00 & 25.00 & 42.60 & 47.33 & 25.50 \\
\hline Giving to classmate & 905.56 & 817.89 & 857.14 & 1050.00 & 880.07 & 780.77 & 853.33 & 861.06 & 740.00 & 842.31 \\
\hline Giving to schoolmate & 711.67 & 686.32 & 721.43 & 839.29 & 613.33 & 415.38 & 617.33 & 452.78 & 600.00 & 623.08 \\
\hline Cooperation: contrib. & 610.50 & 639.47 & 689.29 & 735.93 & 618.40 & 457.31 & 645.87 & 701.11 & 590.00 & 529.23 \\
\hline Trust: sum sent & 494.44 & 563.16 & 650.00 & 642.86 & 713.33 & 515.38 & 553.33 & 588.89 & 550.00 & 453.85 \\
\hline Trust: $\%$ returned & 42.74 & 39.12 & 45.05 & 48.17 & 46.44 & 38.77 & 44.06 & 40.13 & 41.31 & 34.24 \\
\hline Competitive & 0.72 & 0.68 & 0.71 & 0.43 & 0.80 & 0.62 & 0.60 & 0.61 & 0.60 & 0.62 \\
\hline Competitive, female & 0.73 & 0.58 & 0.67 & 0.25 & 0.78 & 0.56 & 0.50 & 0.58 & 0.57 & 0.60 \\
\hline Competitive, male & 0.71 & 0.86 & 0.71 & 0.67 & 0.83 & 0.75 & 0.75 & 0.80 & 0.67 & 0.50 \\
\hline
\end{tabular}

Table 7. Descriptive data from school $\mathrm{KB}$

\subsection{School MK}

School MK was the first non-Budapest based school in our sample. 98 students from five school groups participated, $55 \%$ of whom were female. Three out of the five groups were non-academic, vocational secondary school classes. No technical difficulties were encountered.

\begin{tabular}{lrrrrr}
\hline Group & 1 & 2 & 3 & 4 & 5 \\
\hline \hline Academic & 0 & 0 & 1 & 1 & 0 \\
Grade & 10 & 10 & 9 & 10 & 17 \\
Subject & 22 & 19 & 16 & Time now vs. 2 \\
& & & & 24 \\
Game For Payment & Competition & Dictator & Competition & Public good game & weeks \\
\hline Female & 0.05 & 0.58 & 0.69 & 0.71 & 0.79 \\
Age & 16.82 & 16.89 & 16.81 & 16.53 & 16.67 \\
Indifference amount now & 1580.91 & 1667.78 & 1486.67 & 1568.00 & 1538.33 \\
Indifference amount 4 weeks & 1422.73 & 1642.35 & 1490.00 & 1550.67 & 1467.08 \\
Risk: \# of boxes & 32.41 & 25.74 & 35.19 & 28.35 & 29.46 \\
Risk, female & 42.00 & 20.27 & 31.64 & 30.50 & 29.05 \\
Risk, male & 31.95 & 33.25 & 43.00 & 23.20 & 31.00 \\
Giving to classmate & 877.27 & 692.89 & 819.06 & 926.47 & 927.08 \\
Giving to schoolmate & 622.73 & 579.53 & 712.81 & 594.12 & 650.00 \\
Cooperation: contribution & 541.18 & 536.84 & 725.00 & 608.82 & 629.17 \\
Trust: sum sent & 540.91 & 452.63 & 593.75 & 505.88 & 550.00 \\
Trust: \% returned & 45.39 & 34.64 & 44.76 & 41.75 & 44.44 \\
Competitive & 0.68 & 0.74 & 0.44 & 0.29 & 0.79 \\
Competitive, female & 1.00 & 0.64 & 0.45 & 0.33 & 0.74 \\
Competitive, male & 0.67 & 0.88 & 0.40 & 0.20 & 1.00
\end{tabular}

Table 8. Descriptive data from school MK

Students in this school were on average the most impatient in our sample. They were more generous and less cooperative than the average; they also trusted their peers less. In the two academic classes, the willingness to compete was extremely low compared to the other 
groups. Despite this, students had average competitiveness rates, but below-average risk-taking willingness. Differences between group-level measures are large in this school as well.

\subsection{School SZB}

We visited four school groups with 70 students, $41 \%$ of them were female. All groups were academic classes. This school operates in a smaller Hungarian town and has strong relations with the Calvinist church.

Although no technical difficulties arose, many students from the participating classes were absent due to a choir competition which was taking place at the time of our experiment. We have to take this into account when assessing the effect of the gender composition of groups on the preferences. For instance, SZB is one of the three schools where female students are more competitive on average than their male schoolmates, although the proportion of female students among the actual participants was low.

There are three schools with an exceptionally high level of risk aversion. Despite the above-average willingness to compete, school SZB is one of these. Cooperation and trust measures from this school are also among the lowest in the sample.

\begin{tabular}{lrrrr}
\hline Group & 1 & 2 & 3 & 4 \\
\hline \hline Academic & 1 & 1 & 1 & 1 \\
Grade & 11 & 11 & 12 & 12 \\
Subject & 22 & 13 & 20 & 15 \\
Game For Payment & Public good game & Trust game & Competition & Competition \\
\hline Female & 0.36 & 0.50 & 0.45 & 0.33 \\
Age & 17.00 & 16.75 & 17.85 & 17.53 \\
Indifference amount now & 1517.73 & 1406.92 & 1436.11 & 1447.33 \\
Indifference amount 4 weeks & 1412.86 & 1538.46 & 1383.00 & 1417.33 \\
Risk: \# of boxes & 28.82 & 28.23 & 30.45 & 29.79 \\
Risk, female & 22.38 & 24.67 & 26.33 & 38.80 \\
Risk, male & 32.50 & 32.33 & 33.82 & 24.78 \\
Giving to classmate & 763.64 & 800.00 & 852.50 & 823.67 \\
Giving to schoolmate & 654.55 & 465.38 & 474.00 & 480.00 \\
Cooperation: contribution & 520.45 & 583.85 & 521.50 & 491.33 \\
Trust: sum sent & 509.09 & 446.15 & 440.00 & 613.33 \\
Trust: $\%$ returned & 41.28 & 45.54 & 42.33 & 41.87 \\
Competitive & 0.64 & 0.85 & 0.80 & 0.80 \\
Competitive, female & 0.75 & 0.83 & 0.67 & 1.00 \\
Competitive, male & 0.57 & 0.83 & 0.91 & 0.70
\end{tabular}

Table 9. Descriptive data from school SZB 


\subsection{School PB}

School PB is a Catholic school operating in Budapest. We measured the preferences of 99 students from 4 academic classes. $56 \%$ of the participants were female. School PB was the only institution with two students opting out of participation. They would have been in Group 4. During the second group session, the program froze, but after restarting the zLeaf clients, everyone was able to continue playing without any data loss. Some students had to type in their answers to the trust game again.

These students were the most patient in the sample. Besides, this school has a great gender difference in risk-taking and willingness to compete, with male students being more risk-tolerant and competitive.

\begin{tabular}{|c|c|c|c|c|}
\hline Group & 1 & 2 & 3 & 4 \\
\hline$\overline{\text { Academic }}$ & 1 & 1 & 1 & $\overline{1}$ \\
\hline Grade & 12 & 11 & 11 & 9 \\
\hline Subject & 25 & 20 & 20 & 34 \\
\hline Game For Payment & Time 4 weeks vs. 6 weeks & $\begin{array}{r}\text { Time } 4 \text { weeks vs. } 6 \\
\text { weeks }\end{array}$ & Competition & Risk \\
\hline Female & 0.60 & 0.53 & 0.60 & 0.53 \\
\hline Age & 17.83 & 16.84 & 16.95 & 14.88 \\
\hline Indifference amount now & 1266.40 & 1291.58 & 1344.74 & 1296.06 \\
\hline Indifference amount 4 weeks & 1350.80 & 1262.00 & 1389.47 & 1389.71 \\
\hline Risk: \# of boxes & 34.24 & 33.37 & 33.50 & 29.29 \\
\hline Risk, female & 30.80 & 31.67 & 23.08 & 28.59 \\
\hline Risk, male & 39.40 & 34.33 & 49.13 & 31.13 \\
\hline Giving to classmate & 638.00 & 662.50 & 755.05 & 838.24 \\
\hline Giving to schoolmate & 492.00 & 530.00 & 345.30 & 547.35 \\
\hline Cooperation: contribution & 558.36 & 603.20 & 615.00 & 605.88 \\
\hline Trust: sum sent & 576.00 & 620.00 & 510.00 & 502.94 \\
\hline Trust: \% returned & 32.86 & 40.47 & 33.49 & 41.83 \\
\hline Competitive & 0.64 & 0.75 & 0.60 & 0.50 \\
\hline Competitive, female & 0.60 & 0.60 & 0.58 & 0.35 \\
\hline Competitive, male & 0.70 & 0.89 & 0.63 & 0.60 \\
\hline
\end{tabular}

Table 10. Descriptive data from school PB

\subsection{School KB2}

KB2 was the school with the highest rate of female participants (90\%), because it is both a high school and a healthcare vocational school. A total of 65 students attended our experimental sessions in four classes. Only one of the classes were academic. This school is located in Budapest. The school belongs to the Catholic Church, but compared to the other religious schools (SZB, PB) this school was less spiritual. 
School KB2 is among the three schools with extremely high risk aversion; in fact, students in KB2 are the most risk-averse in the whole sample. Average cooperation and trust levels are also the lowest among all schools; competitiveness is below average as well. There is only one school with more impatient students than this school (MK). Lastly, these groups were more generous than the average.

\begin{tabular}{lrrrr}
\hline Group & 1 & 2 & 3 & 4 \\
\hline \hline Academic & 0 & 1 & 0 & 0 \\
Grade & 9 & 9 & 10 & 10 \\
Subject & 17 & 17 & 22 & 9 \\
Game For Payment & Competition & Risk & Trust game & Public good game \\
\hline Female & 0.94 & 0.81 & 0.90 & 1.00 \\
Age & 15.76 & 15.63 & 16.14 & 16.67 \\
Indifference amount now & 1374.38 & 1552.50 & 1440.95 & 1812.22 \\
Indifference amount 4 weeks & 1491.88 & 1572.35 & 1504.55 & 1640.00 \\
Risk: \# of boxes & 30.35 & 28.71 & 23.09 & 22.67 \\
Risk, female & 29.13 & 33.23 & 22.74 & 22.67 \\
Risk, male & 50.00 & 13.33 & 37.50 & 84.45 \\
Giving to classmate & 858.82 & 879.41 & 827.27 & 600.00 \\
Giving to schoolmate & 632.35 & 576.47 & 625.00 & 425.33 \\
Cooperation: contribution & 494.12 & 480.41 & 580.64 & 45.56 \\
Trust: sum sent & 429.41 & 482.35 & 522.73 & 27.43 \\
Trust: $\%$ returned & 32.47 & 42.95 & 35.43 & 0.44 \\
Competitive & 0.24 & 0.65 & 0.68 & 0.44 \\
Competitive, female & 0.25 & 0.69 & 0.68 & 0.50 \\
Competitive, male & 0.00 & 0.33 & &
\end{tabular}

Table 11. Descriptive data from school KB2

\subsection{School NE}

103 students from four academic classes participated in the assessment from school NE, an institution located in a rural Hungarian town. $56 \%$ of the students were female.

Our program froze during the first session while participants were at the competition game. This must have affected our data because after the restart, the program continued at the very end of the competition round the students were in, without allowing them to complete the task. We take into account these technical difficulties in our data by creating a dummy variable for those students who were affected by this problem.

Students in NE were more impatient than the average, and all of their social preference measures were below-average. Their risk and competitiveness measures were around the sample mean, but we see different results by gender. Female students in NE were more risk- 
tolerant and competitive than the average of all female students in our sample, and the opposite is true for male students.

\begin{tabular}{lrrrr}
\hline Group & 1 & 2 & 3 & 4 \\
\hline \hline Academic & 1 & 1 & 1 & 1 \\
Grade & 11 & 11 & 11 & 11 \\
Subject & 27 & 24 & 33 & 19 \\
Game For Payment & Dictator & Time 4 weeks vs. 6 weeks & Trust game & Dictator \\
\hline Female & 0.38 & 0.79 & 0.55 & 0.53 \\
Age & 17.04 & 17.83 & 17.45 & 17.47 \\
Indifference amount now & 1517.78 & 1443.18 & 1479.09 & 1498.82 \\
Indifference amount 4 weeks & 1435.38 & 1367.83 & 1509.39 & 1453.33 \\
Risk: \# of boxes & 38.31 & 37.96 & 34.12 & 31.95 \\
Risk, female & 33.33 & 37.42 & 29.17 & 40.00 \\
Risk, male & 40.38 & 40.00 & 40.07 & 23.00 \\
Giving to classmate & 767.04 & 741.67 & 553.33 & 560.79 \\
Giving to schoolmate & 490.74 & 475.00 & 524.85 & 275.00 \\
Cooperation: contribution & 698.96 & 534.17 & 550.15 & 562.58 \\
Trust: sum sent & 644.44 & 537.50 & 509.09 & 500.00 \\
Trust: $\%$ returned & 41.96 & 36.41 & 34.13 & 37.07 \\
Competitive & 0.59 & 0.54 & 0.67 & 0.53 \\
Competitive, female & 0.70 & 0.53 & 0.67 & 0.50 \\
Competitive, male & 0.50 & 0.60 & 0.67 & 0.56
\end{tabular}

Table 12. Descriptive data from school NE

\subsection{School KK}

We assessed the preference measures of 166 students from 7 academic school groups in school KK that operates in a rural town. $66 \%$ of the participants were female. Although the program froze during the competition game at Group 7, it only affected four people. They were not able to complete one of the three competition rounds which must have affected their results. As before, we take into account these technical difficulties in our data by creating a dummy variable for those students who were affected by this problem.

$\mathrm{KK}$ is the third school with very high risk aversion compared to the sample mean. However, the willingness to compete on school level (female and male students combined) is exactly the same as the average (although male students are far more competitive than their female peers).

We measured the most significant average difference between the two indifference points in time in this school. Students here were much more patient in the present than in the future. The level of generosity was around average, but the measures of cooperation and trust were below-average. 


\begin{tabular}{|c|c|c|c|c|c|c|c|}
\hline Group & 1 & 2 & 3 & 4 & 5 & 6 & 7 \\
\hline Academic & 1 & 1 & 1 & 1 & 1 & 1 & $\overline{1}$ \\
\hline Grade & 9 & 10 & 9 & 10 & 9 & 10 & 11 \\
\hline Subject & \multirow{2}{*}{\multicolumn{7}{|c|}{ Time 4 weeks vs. Time 4 weeks vs. }} \\
\hline & & & & & & & \\
\hline Game For Payment & Public good game & Risk & 6 weeks & 6 weeks & Risk & Trust game & Risk \\
\hline Female & 0.79 & 0.58 & 0.87 & 0.87 & 0.32 & 0.22 & 0.75 \\
\hline Age & 15.75 & 16.71 & 15.78 & 16.70 & 15.74 & 16.89 & 17.79 \\
\hline Indifference amount now & 1438.52 & 1378.26 & 1409.55 & 1278.28 & 1421.05 & 1356.11 & 1400.00 \\
\hline Indifference amount 4 weeks & 1551.48 & 1367.73 & 1589.57 & 1465.33 & 1511.05 & 1317.22 & 1508.33 \\
\hline Risk: \# of boxes & 24.07 & 34.25 & 22.57 & 27.50 & 28.95 & 34.56 & 39.00 \\
\hline Risk, female & 22.18 & 33.36 & 20.70 & 28.85 & 15.00 & 17.00 & 39.59 \\
\hline Risk, male & 31.00 & 35.50 & 35.00 & 18.75 & 35.38 & 39.57 & 37.00 \\
\hline Giving to classmate & 960.71 & 846.04 & 826.09 & 831.70 & 873.63 & 594.39 & 658.33 \\
\hline Giving to schoolmate & 705.00 & 566.88 & 586.96 & 621.67 & 555.21 & 394.44 & 518.75 \\
\hline Cooperation: contribution & 621.39 & 566.58 & 503.48 & 515.30 & 588.68 & 652.78 & 595.42 \\
\hline Trust: sum sent & 528.57 & 545.83 & 482.61 & 456.67 & 473.68 & 450.00 & 583.33 \\
\hline Trust: \% returned & 40.33 & 37.89 & 36.24 & 34.80 & 35.24 & 39.92 & 40.74 \\
\hline Competitive & 0.50 & 0.63 & 0.65 & 0.53 & 0.68 & 0.89 & 0.54 \\
\hline Competitive, female & 0.45 & 0.50 & 0.65 & 0.54 & 0.33 & 0.50 & 0.56 \\
\hline Competitive, male & 0.67 & 0.80 & 0.67 & 0.50 & 0.85 & 1.00 & 0.50 \\
\hline
\end{tabular}

Table 13. Descriptive data from school KK

\subsection{School KSZ}

There were 105 participants in 5 school groups, two of which were academic classes.

The other three were vocational secondary school classes. $66 \%$ of the students were female.

ZTree froze during the competition game at Group 3, but it did not affect all zLeaf clients. The results of those who were not able to complete one of the three competition rounds must have been affected by this accident. We take into account these technical difficulties in our data by creating a dummy variable for those students who were affected by this problem.

The school could not access the NABC ID-s of the students in Group 2 and 3 at the time of the experiment, and in the absence of these, we were also not able to retrieve background data regarding these two groups. The breakdown of competition preferences by gender is hence incomplete.

We measured the second biggest average difference between the two indifference points in time in this school, with students being more patient in the present. Generosity was also higher than average here. Students in KSZ were less risk-tolerant than the average, but this is mainly driven by female students. The willingness to compete of both male and female students is greater than the sample means by gender. 


\begin{tabular}{|c|c|c|c|c|c|}
\hline Group & 1 & 2 & 3 & 4 & 5 \\
\hline Academic & 0 & 1 & 1 & 0 & 0 \\
\hline Grade & 11 & 10 & 9 & 12 & 12 \\
\hline Subject & 17 & 22 & 30 & 20 & 16 \\
\hline Game For Payment & $\begin{array}{r}\text { Time } 4 \text { weeks vs. } 6 \\
\text { weeks }\end{array}$ & $\begin{array}{r}\text { Time } 4 \text { weeks vs. } 6 \\
\text { weeks }\end{array}$ & Dictator & $\begin{array}{r}\text { Public good } \\
\text { game }\end{array}$ & Dictator \\
\hline Female & 0.69 & & & 0.50 & 0.81 \\
\hline Age & 18.69 & & & 20.00 & 19.13 \\
\hline Indifference amount now & 1366.47 & 1390.00 & 1289.00 & 1357.00 & 1495.00 \\
\hline Indifference amount 4 weeks & 1392.35 & 1444.55 & 1373.67 & 1469.50 & 1593.13 \\
\hline Risk: \# of boxes & 26.29 & 27.41 & 33.97 & 34.20 & 36.25 \\
\hline Risk, female & 24.00 & & & 29.11 & 35.00 \\
\hline Risk, male & 31.80 & & & 40.22 & 41.67 \\
\hline Giving to classmate & 908.82 & 890.91 & 943.33 & 725.25 & 837.50 \\
\hline Giving to schoolmate & 570.59 & 740.91 & 690.00 & 548.75 & 531.25 \\
\hline Cooperation: contribution & 606.18 & 577.50 & 631.87 & 715.00 & 606.56 \\
\hline Trust: sum sent & 576.47 & 545.45 & 500.00 & 585.00 & 543.75 \\
\hline Trust: $\%$ returned & 36.59 & 43.40 & 39.34 & 44.88 & 34.88 \\
\hline Competitive & 0.76 & 0.59 & 0.70 & 0.70 & 0.69 \\
\hline Competitive, female & 0.64 & & & 0.67 & 0.62 \\
\hline Competitive, male & 1.00 & & & 0.78 & 1.00 \\
\hline
\end{tabular}

Table 14. Descriptive data from school KSZ

\section{Validation}

We have measured four types of preferences, and we have data on the sociodemographics of our participants. In this section, we will validate our measurements along two dimensions. On the one hand, there are a few experiments that measure many preferences at the same time, so we can compare if the correlations between the measured preferences found in those experiments are present in our measurement as well. On the other hand, there is a vast literature examining how preferences relate to individual characteristics, so we can check how the findings of the literature compare to ours.

Starting with the correlation between different preferences, Dean and Ortoleva (2019) report the joint distribution of 11 behavioural phenomena, among them many that we also investigate. Here we consider only those correlations that we have an analogue for in our analysis. Note that Dean and Ortoleva (2019) do not study generosity, cooperation and competitiveness. They document a strong positive relationship between time preference measured between now and later and time preference measured between two future dates. Time preference related between two future dates also associates with cognitive ability in their study, more impatient subjects exhibiting lower cognitive ability. Time preference related to choice 
today vs later is related to risk aversion, more risk-averse subjects being less patient. Behaviour in the trust game correlates with neither time nor risk preferences, however sending and returning choices in the trust game show a strong and positive association. The positive relationship between being female and risk aversion is also reported.

Horn and Kiss (2018) use a pool of Hungarian university students to study how different preferences associate with school performance. They measure the same preferences, except trust and generosity. Similarly to Dean and Ortoleva (2019), they find a significant positive association between the present (today vs later) and future (two future dates) time preferences and a negative relationship between future time preference and cognitive abilities. They also report that more risk-averse subjects tend to cooperate less, but have better cognitive skills. Furthermore, they document that females are more risk-averse.

Turning to the relationship between socio-demographics and preferences, Sutter et al. (2019) provide a review of the literature on how preferences are and evolve in children and adolescents. We will check if the associations reported in this review are present in our data as well. Concerning time preferences, they report that patience increases typically with age, but there is no clear gender difference. Socioeconomic status (SES) also relates to time preferences, low SES predicting more impatient choices. Concerning risk preferences, most of the literature reports that females are more risk-averse than males. Low SES associates with more risk-taking.

Turning to social preferences, the literature has documented that females tend to be more generous than males. Low SES correlates with less prosociality. In trust games, trusting behaviour (captured by the amount sent) and trustworthiness (proxied by the amount returned) increase with age. No gender effect is found generally in the trust game. Cooperativeness also typically increases with age. No gender effects are reported in cooperation, and not much is known about the impact of SES. Concerning competitiveness, females generally are less willing to compete than males. Low SES associates with lower competitiveness. 
Table 14 contains a correlation matrix with individual data collected in our research. Considering associations between preferences, we observe a high and significant correlation between our time preference measures, in line with the findings in the literature. As in the literature, we also find that less patient individuals tend to have lower cognitive abilities. Similarly to Dean and Ortoleva (2019), we observe that more risk-averse participants tend to be less patient, and there is also a high correlation between the money sent and returned in the trust game. Contrary to Dean and Ortoleva (2019), sending in the trust game associates significantly both with time and risk preferences: more patient and more risk-tolerant participants send more money in the trust game.

Similarly to Horn and Kiss (2018), we see that more risk tolerance goes hand in hand with cooperation and cognitive abilities as well. Overall, we see most of the correlations in our data that the cited papers exhibit. Moreover, our data reveal that more patient participants tend to be more cooperative and tend to send more in the trust game. Generosity is also positively related to choices in the trust game. ${ }^{15}$

\footnotetext{
${ }^{15}$ Note that most of these significant associations could not be seen in the cited papers as those papers did not study all the preferences that we have in this research.
} 


\begin{tabular}{|c|c|c|c|c|c|c|c|c|c|c|c|c|c|}
\hline Variables & $(1)$ & $(2)$ & $(3)$ & $(4)$ & $(5)$ & $(6)$ & $(7)$ & $(8)$ & $(9)$ & $(10)$ & $(11)$ & $(12)$ & $(13)$ \\
\hline (1) Female & 1.000 & & & & & & & & & & & & \\
\hline (2) Age & 0.038 & 1.000 & & & & & & & & & & & \\
\hline (3) Math6 & $-0.270 *$ & $-0.118 *$ & 1.000 & & & & & & & & & & \\
\hline (4) High SES & $-0.135^{*}$ & $-0.146^{*}$ & $0.386^{*}$ & 1.000 & & & & & & & & & \\
\hline (5) Indifference amount now & -0.005 & 0.037 & $-0.126 *$ & -0.052 & 1.000 & & & & & & & & \\
\hline (6) Indifference amount 4 weeks & $0.105^{*}$ & 0.004 & $-0.246^{*}$ & $-0.146^{*}$ & $0.544^{*}$ & 1.000 & & & & & & & \\
\hline (7) Risk: \# of boxes & $-0.171 *$ & 0.060 & $0.251 *$ & $0.104 *$ & 0.018 & $-0.122 *$ & 1.000 & & & & & & \\
\hline (8) Giving to classmate & $0.156^{*}$ & -0.026 & $-0.132 *$ & -0.018 & -0.048 & 0.021 & $-0.142 *$ & 1.000 & & & & & \\
\hline (10) Cooperation: contribution & $-0.067 *$ & -0.002 & $0.190 *$ & $0.065^{*}$ & $-0.087 *$ & $-0.088 *$ & $0.140 *$ & $0.138 *$ & $0.126^{*}$ & 1.000 & & & \\
\hline (11) Trust: sum sent & $-0.166^{*}$ & 0.029 & $0.210^{*}$ & $0.123^{*}$ & $-0.061 *$ & $-0.121 *$ & $0.215^{*}$ & $0.266^{*}$ & $0.230^{*}$ & $0.450 *$ & 1.000 & & \\
\hline (12) Trust: \% returned & $-0.090 *$ & 0.044 & -0.023 & -0.022 & -0.014 & -0.014 & 0.003 & $0.294 *$ & $0.270^{*}$ & $0.252 *$ & $0.324 *$ & 1.000 & \\
\hline (13) Competitive & $-0.098 *$ & $0.072 *$ & -0.031 & -0.049 & 0.043 & -0.025 & $0.091 *$ & -0.028 & -0.012 & 0.033 & 0.047 & 0.030 & 1.000 \\
\hline
\end{tabular}

NOTES: * shows significance at the 0.05 level

High SES: Dummy $=1$ if at least one of the parents has a diploma

Math6: Math score in the National Assessment of Basic Competences, a proxy for cognitive abilities

Larger indifference amounts indicate less patience.

Our risk measure (\# of boxes collected) indicates in fact risk tolerance, so the higher is this number, the less risk-averse is the participant.

Trust: sum returned: It is the average of the shares returned to the sender in the trust game for different amounts of money received

Competitive: Dummy, 0- piece rate payment, 1 - tournament payment

Table 15. Pairwise correlations of background variables and preference measures (without the data of the Pilot school) 
Turning to the associations between socio-demographics and preferences, we do not see any relationship between age and patience, though the sign coincides with what we have in the literature. This may be because the literature investigates a longer age span while our participants are all 15-20 years old. Regarding the association between gender and patience, our correlations are in line with the literature in the sense that there is no strong result as on the short horizon, we do not see any association. In contrast, on the long horizon females tend to be more impatient. Socioeconomic status has the same effect on patience as in the literature as on both horizons participants with a better family background are more patient. On a longer horizon, the relationship is significant.

In line with the literature, females are significantly more risk-averse than males in our sample. However, we observe a positive association between risk tolerance and family background, contrary to findings reported in Sutter et al. (2019). We also observe in our data that participants with better cognitive abilities are more risk-tolerant, an association also reported by Dohmen et al. (2010).

In line with the literature, females are significantly more generous (captured by the giving behaviour to classmates and schoolmates) than males in our sample. However, while the sign coincides with that of the literature, we do not document a significant relationship between family background and generosity. Even though the sign is in line with the findings in the literature, we do not see a significant association between age and choices in the trust game, contrary to previous research. In our sample, females send and return significantly less than males, as opposed to the literature. We observe the same patterns as of cooperativeness. Regarding competitiveness, in line with the literature females are less competitive. While the literature is mixed on the effect of age, older participants in our sample tend to compete more. We also observe a significant and positive relationship between competitiveness and risk tolerance. 
Overall, although on some points the correlations in our data do not agree with those reported in the literature, in most of the cases, our findings coincide with what other researchers found. Thus, we consider that we successfully measured the preferences of the students.

\section{Conclusion}

This paper documents the experiments that we carried out in 10 Hungarian high schools from March 2018 to March 2020. We described the preferences that we measured using experimental tasks, and we also reported the execution of the experiments. Furthermore, we presented the main descriptive statistics aggregated over all schools, but also on a school and class level. We carried out a validation exercise to show that our measurements are in line with previous research. 


\section{References}

Abeler, J., Falk, A., Goette, L. \& Huffman, D. (2011). Reference points and effort provision. American Economic Review, 101(2), 470-92.

Andreoni, J., Kuhn, M. A. \& Sprenger, C. (2015). Measuring time preferences: A comparison of experimental methods. Journal of Economic Behavior \& Organization, 116, 451464.

Berg, J., Dickhaut, J. \& McCabe, K. (1995). Trust, reciprocity, and social history. Games and Economic Behavior, 10(1), 122-142.

Bertrand, M. (2011). New perspectives on gender. In Handbook of Labor Economics (Vol. 4, pp. 1543-1590). Elsevier.

Chaudhuri, A. (2011). Sustaining cooperation in laboratory public goods experiments: a selective survey of the literature. Experimental Economics, 14(1), 47-83.

Cohen, J. D., Ericson, K. M., Laibson, D. \& White, J. M. (2016). Measuring time preferences. National Bureau of Economic Research.

Cornsweet, T. N. (1962). The staircase-method in psychophysics. The American Journal of Psychology, 75(3), 485-491.

Crosetto, P. \& Filippin, A. (2013). The "bomb" risk elicitation task. Journal of Risk and Uncertainty, 47(1), 31-65.

Crosetto, P. \& Filippin, A. (2016). A theoretical and experimental appraisal of four risk elicitation methods. Experimental Economics, 19(3), 613-641.

Croson, R. \& Gneezy, U. (2009). Gender differences in preferences. Journal of Economic Literature, 47(2), 448-74.

Dean, M. \& Ortoleva, P. (2019). The empirical relationship between nonstandard economic behaviors. Proceedings of the National Academy of Sciences, 116(33), 16262-16267. 
Dohmen, T., Falk, A., Huffman, D. \& Sunde, U. (2010). Are risk aversion and impatience related to cognitive ability? American Economic Review, 100(3), 1238-60.

Eckel, C. C. \& Grossman, P. J. (2002). Sex differences and statistical stereotyping in attitudes toward financial risk. Evolution and Human Behavior, 23(4), 281-295.

Falk, A., Becker, A., Dohmen, T., Enke, B., Huffman, D. \& Sunde, U. (2018). Global evidence on economic preferences. The Quarterly Journal of Economics, 133(4), 1645-1692.

Fischbacher, U. (2007). z-Tree: Zurich toolbox for ready-made economic experiments. Experimental Economics, 10(2), 171-178.

Gill, D. \& Prowse, V. (2019). Measuring costly effort using the slider task. Journal of Behavioral and Experimental Finance, 21, 1-9.

Gneezy, U. \& Potters, J. (1997). An experiment on risk taking and evaluation periods. The Quarterly Journal of Economics, 112(2), 631-645.

Holt, C. A. \& Laury, S. K. (2002). Risk aversion and incentive effects. American Economic Review, 92(5), 1644-1655.

Horn, D. \& Kiss, H. J. (2018). Which preferences associate with school performance?Lessons from an exploratory study with university students. PLoS ONE, 13(2).

Johnson, N. D. \& Mislin, A. A. (2011). Trust games: A meta-analysis. Journal of Economic Psychology, 32(5), 865-889.

Lénárd, T., Horn, D. \& Kiss, H. J. (2020). Does Politicizing 'Gender’ Influence the Possibility of Conducting Academic Research? Evidence from a Randomized Controlled Trial. Economics Letters, 189, 109022.

Niederle, M. \& Vesterlund, L. (2007). Do women shy away from competition? Do men compete too much?. The Quarterly Journal of Economics, 122(3), 1067-1101.

Niederle, M. \& Vesterlund, L. (2011). Gender and Competition. Annual Review of Economics, 3, 601-630. 
Sutter, M., Zoller, C. \& Glätzle-Rützler, D. (2019). Economic behavior of children and adolescents-A first survey of experimental economics results. European Economic Review, 111, 98-121. 


\section{Appendices}

\subsection{Appendix A - Instructions}

Dear participant!

First of all, we would like to thank you for your participation in this experiment. The data collected during the experiment will be used for research purposes at the Institute of Economics of the Centre for Economic and Regional Studies.

Participation is VOLUNTARY. You can quit the experiment at any time without having to give any justification, or you may deny answering questions.

During the experiment, you will participate in 8 small games in which you will have to make different choices. You need to know that there is no objectively right answer in any of the decisions. Moreover, we are not interested in individual decisions, but in how people decide in such situations on average. Before each decision, we will describe the situation in detail and we will explain what the choice is about. If the description or the explanation is not clear, please raise your hand, and the experimenter will answer your question.

You should know that depending on your choices, you will earn canteen vouchers at the end of the experiment. More precisely, at the end of the experiment, we will pick one of the games randomly, and your decision in that game determines your earning. You can use the vouchers that you earn instead of money in the canteen of the school until the date that you see on the blackboard.

Note that in some situations, the earnings do not depend on your decision only, but also on the decision of another participant. We will describe in the presentation of each situation how the earnings would be determined if that game were picked for payment. The payment will take place after the experiment. You will receive the vouchers here in the room.

Participation in the research is ANONYMOUS. During the experiment, we will not ask for any personal data. Your answers will be linked to the data of the National Assessment of 
Basic Competences using your NABC ID. No data will be given to third parties. We will treat all information that we collect during the research confidentially.

Please, remain silent during the experiment and do not disturb each other. It is forbidden to talk! Should you have a question, turn to the experimenter. Please, silence your mobile phone! Those who misbehave will be excluded from the experiment. In an extreme case, we may exclude the whole group, and nobody will earn anything.

Thank you for your cooperation! 
7.2 Appendix B - Measurement of time preferences with the staircase method

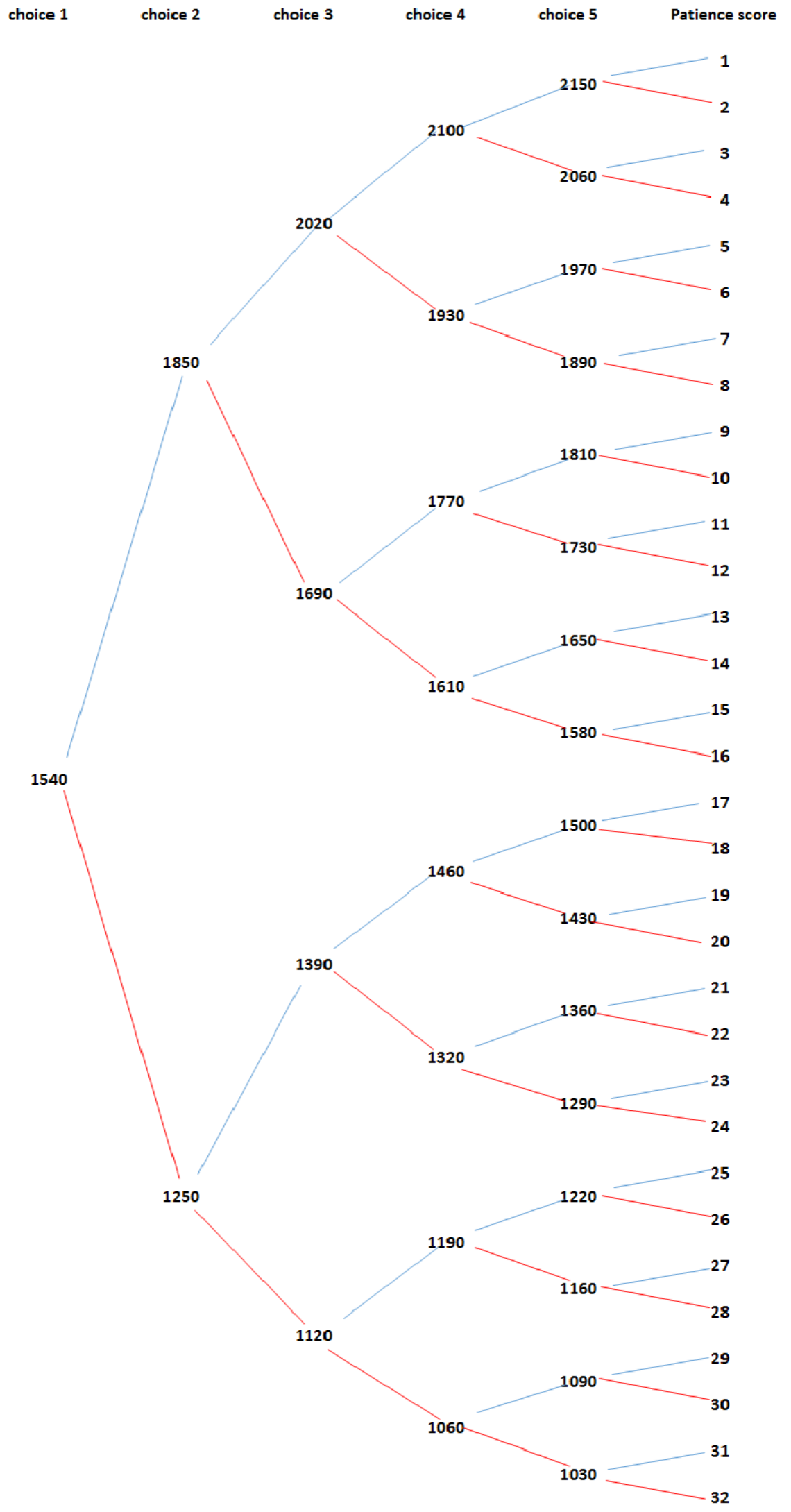




\subsection{Appendix C - Visualization of between-school heterogeneity}

Probability density functions - all schools together:
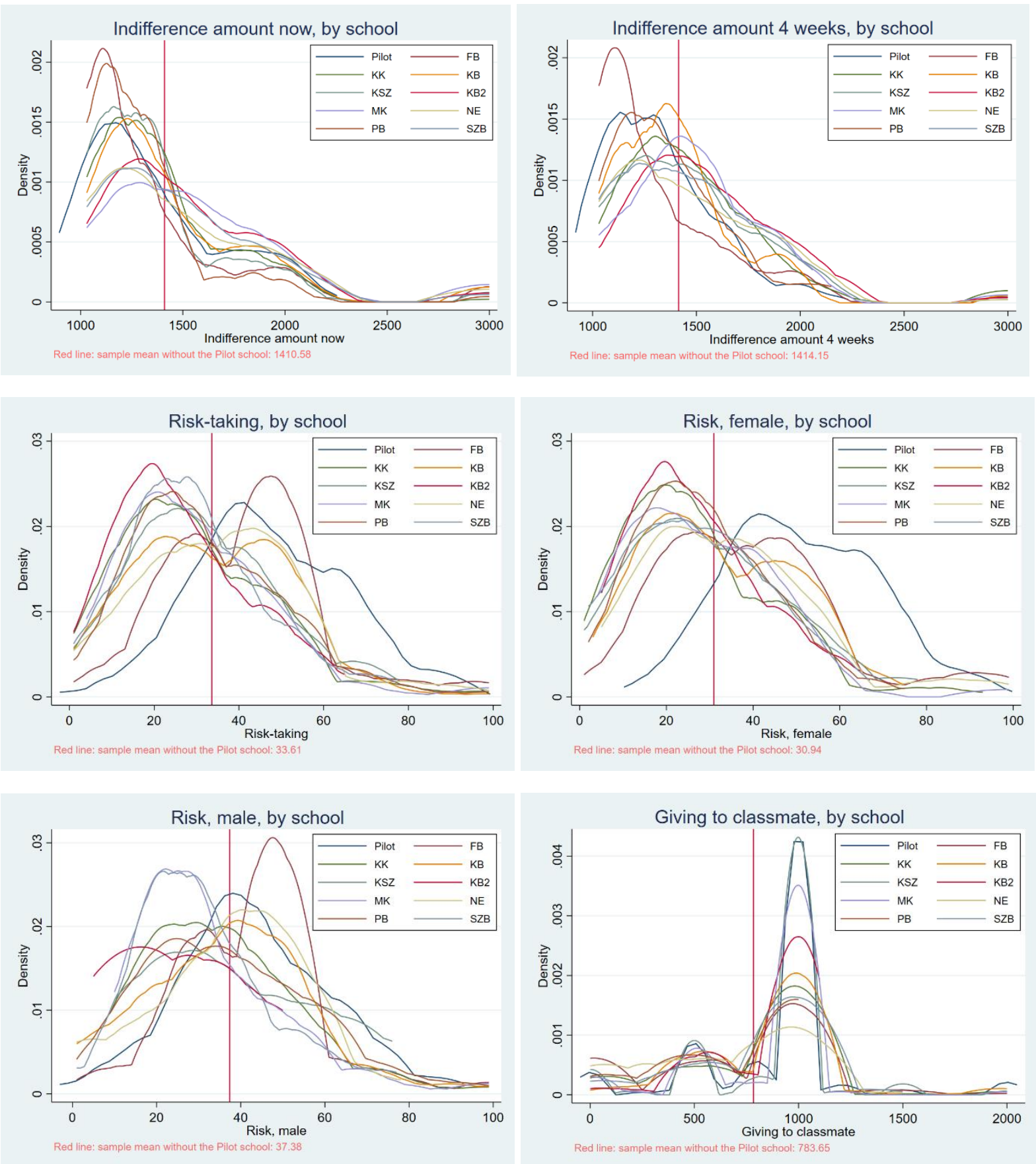

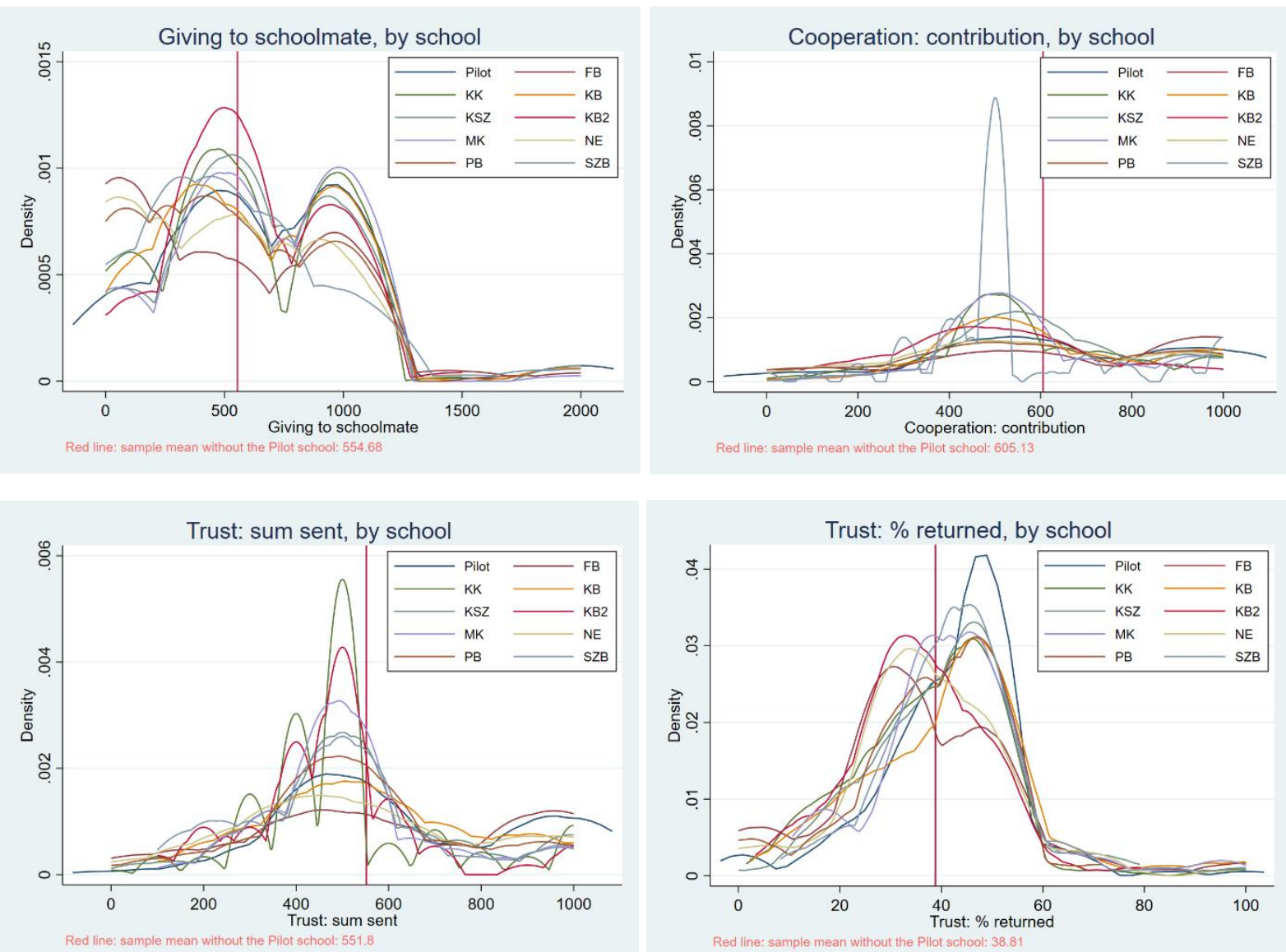

Probability density functions - schools separated:

\section{Indifference amount now, by school}
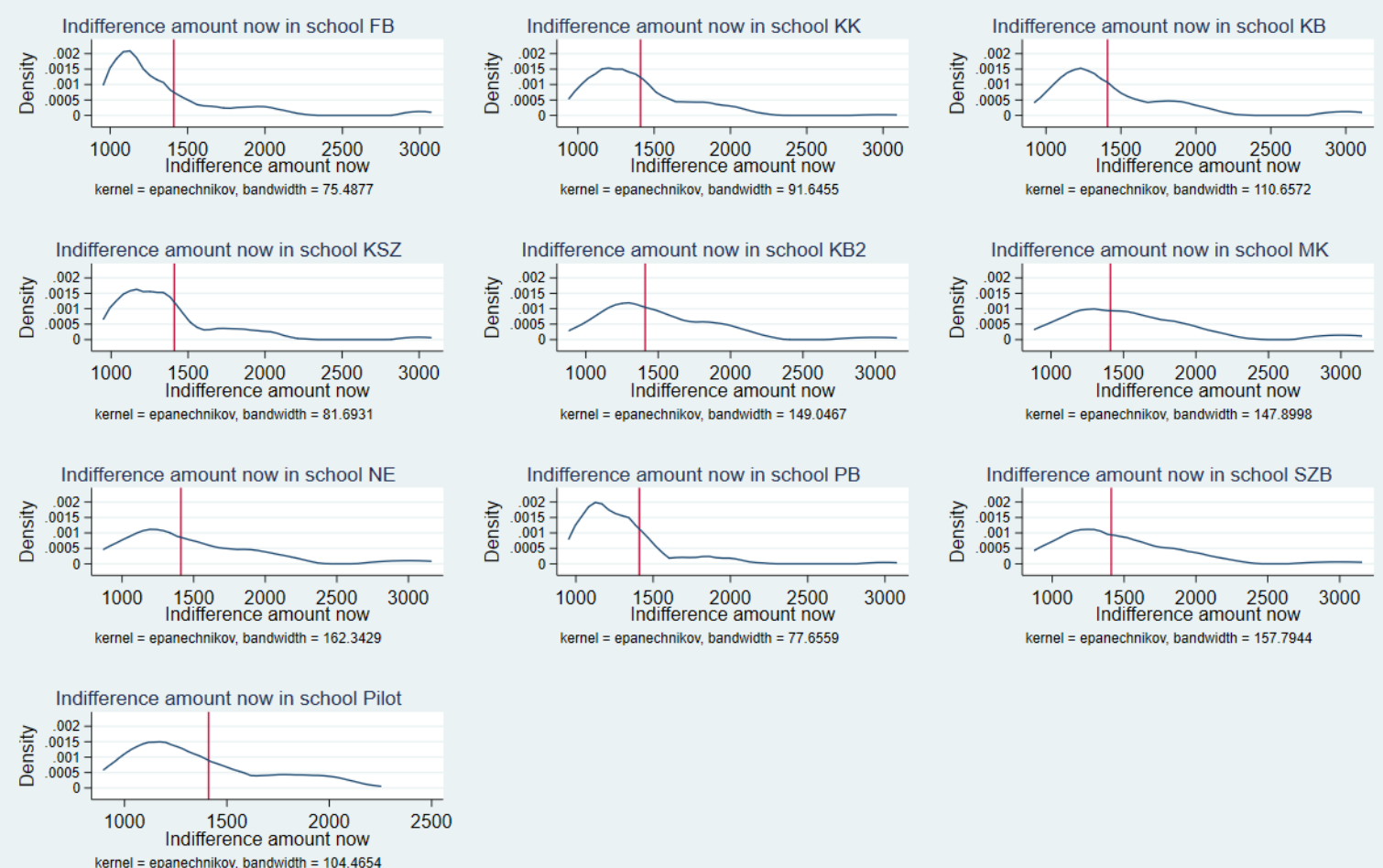

Red line: sample mean without the Pilot school: 1410.58 


\section{Indifference amount 4 weeks, by school}
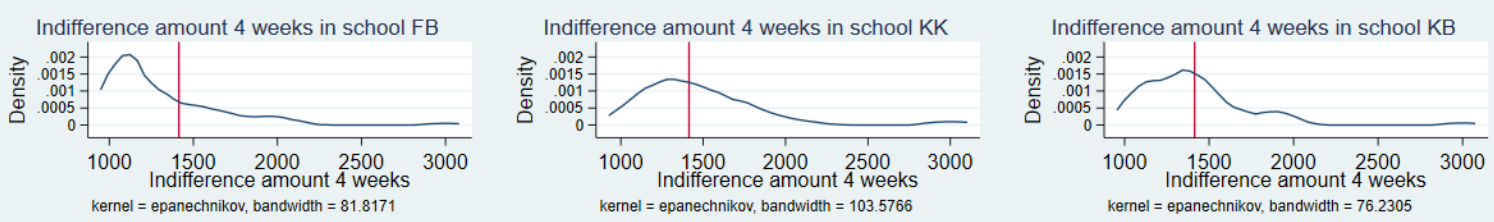

Indifference amount 4 weeks in school KSZ

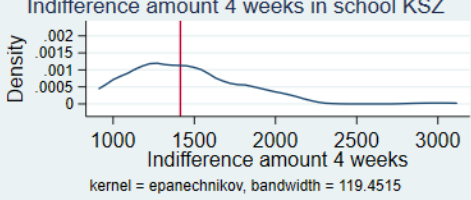

Indifference amount 4 weeks in school KB2

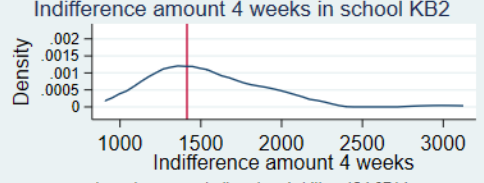

Indifference amount 4 weeks in school MK

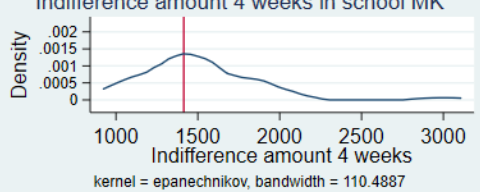

Indifference amount 4 weeks in school NE kernel $=$ epanechnikov, bandwidth $=124.8714$ kernel $=$ epanechnikov, bandwidth $=110.4887$

Indifference amount 4 weeks in school PB

Indifference amount 4 weeks in school SZB
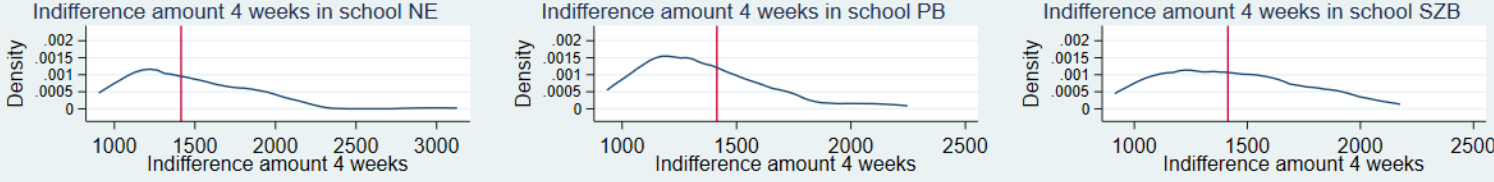

kernel $=$ epanechnikov, bandwidth $=1280600$

kernel $=$ epanechnikov, bandwidth $=97.5551$

Indifference amount 4 weeks
kernel $=$ epanechnikov, bandwidth $=116.4419$

Indifference amount 4 weeks in school Pilo

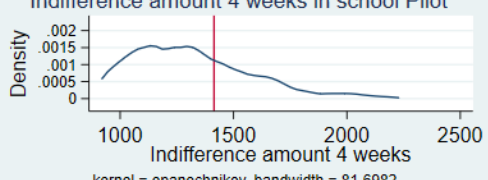

kernel $=$ epanechnikov, bandwidth $=81.6982$

Red line: sample mean without the Pilot school: 1414.15

\section{Risk-taking, by school}
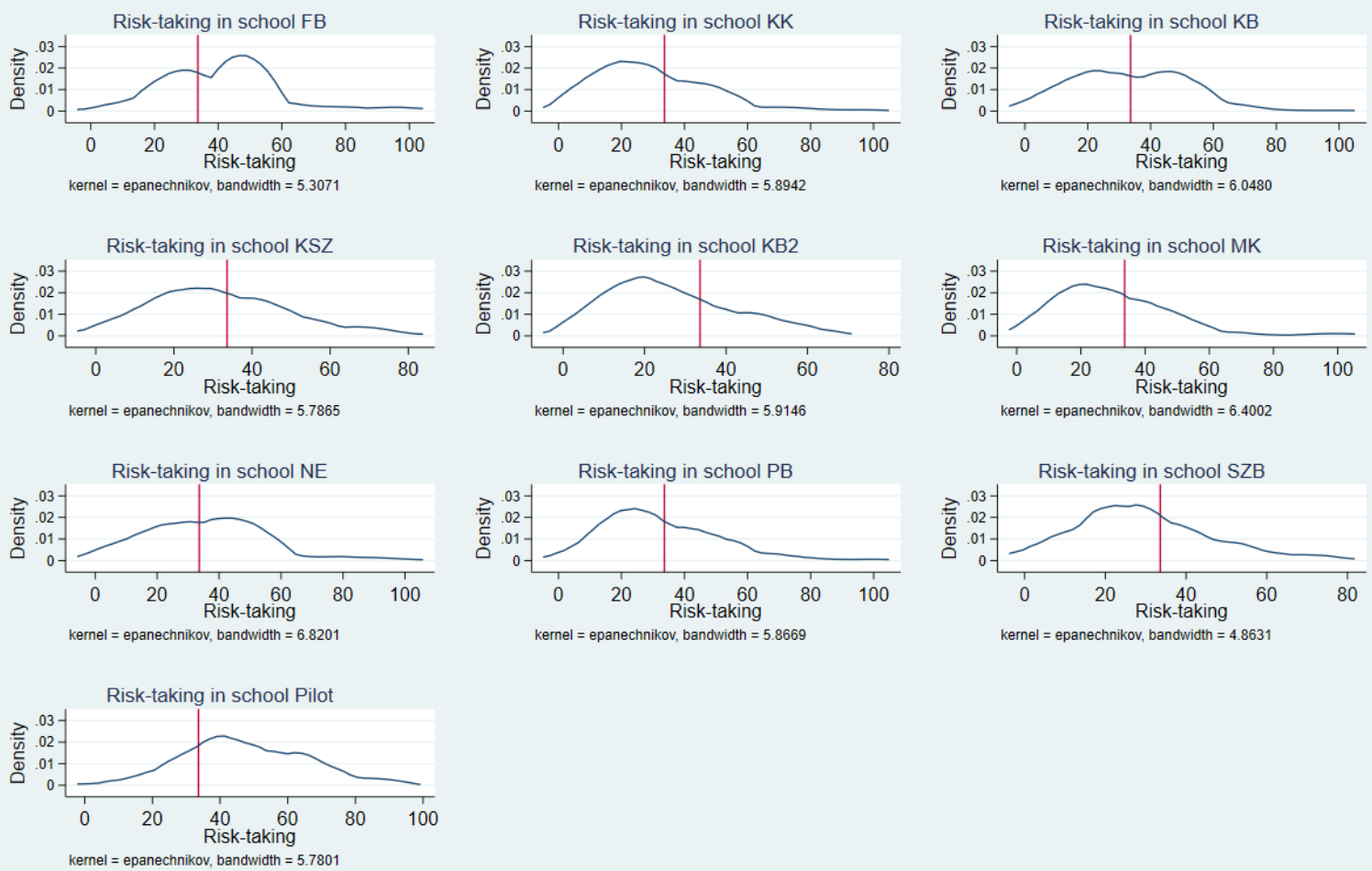

Red line: sample mean without the Pilot school: 33.61 


\section{Risk, female, by school}
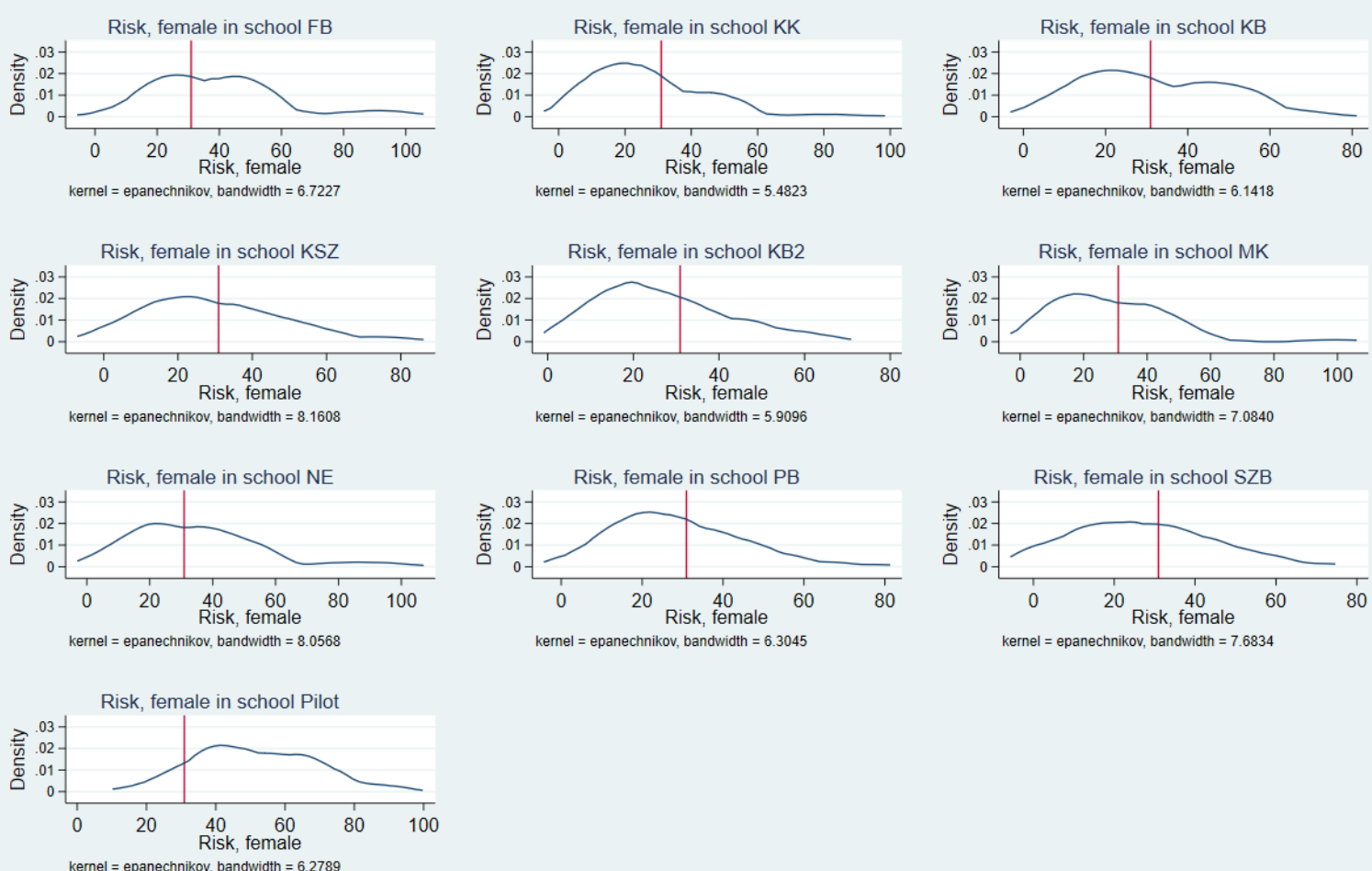

kernel $=$ epanechnikov, bandwidth $=6.3045$

kernel $=$ epanechnikov, bandwidth $=7.6834$

Red line: sample mean without the Pilot school: 30.94

\section{Risk, male, by school}
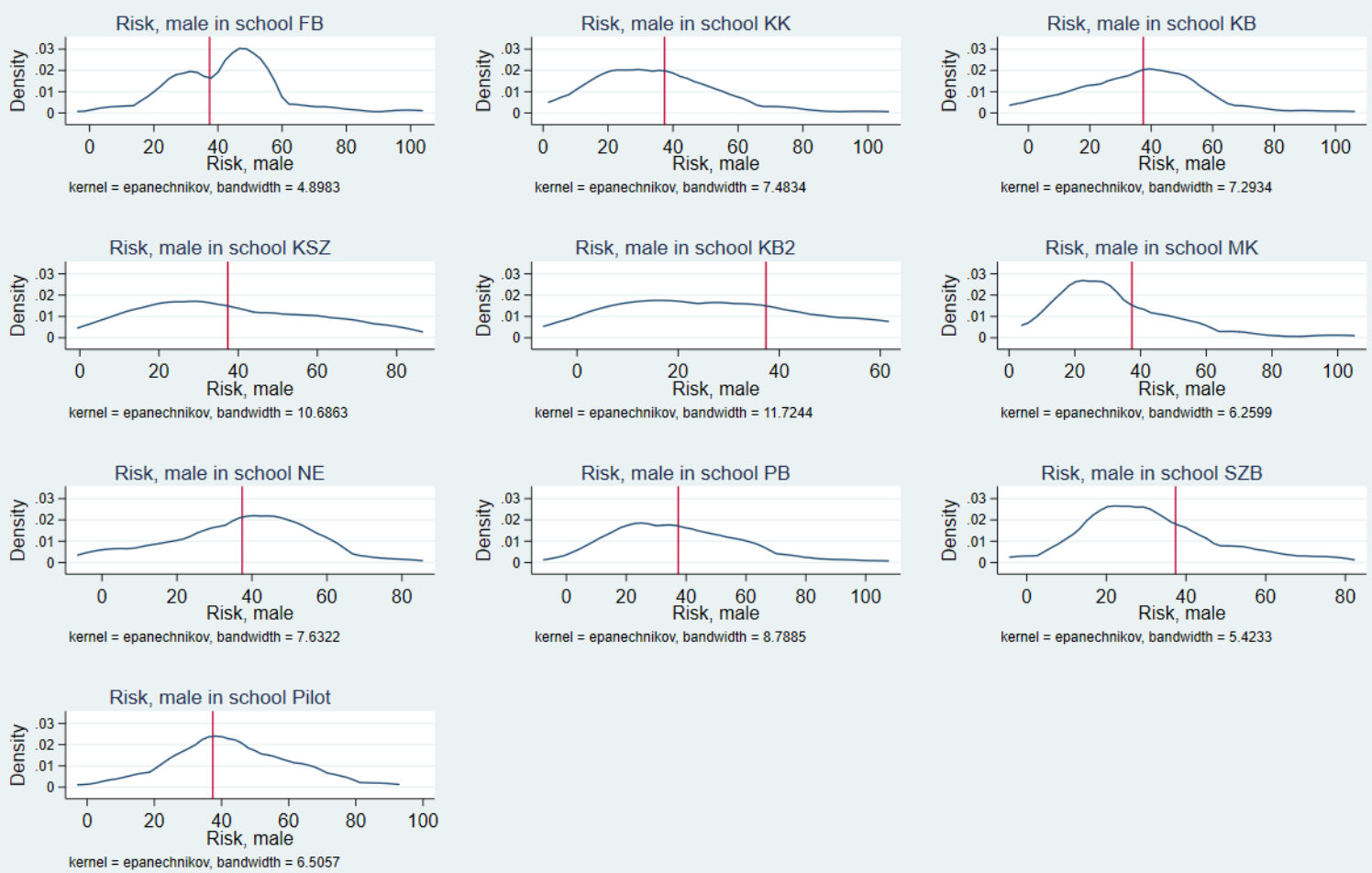

Red line: sample mean without the Pilot school: 37.38 


\section{Giving to classmate, by school}
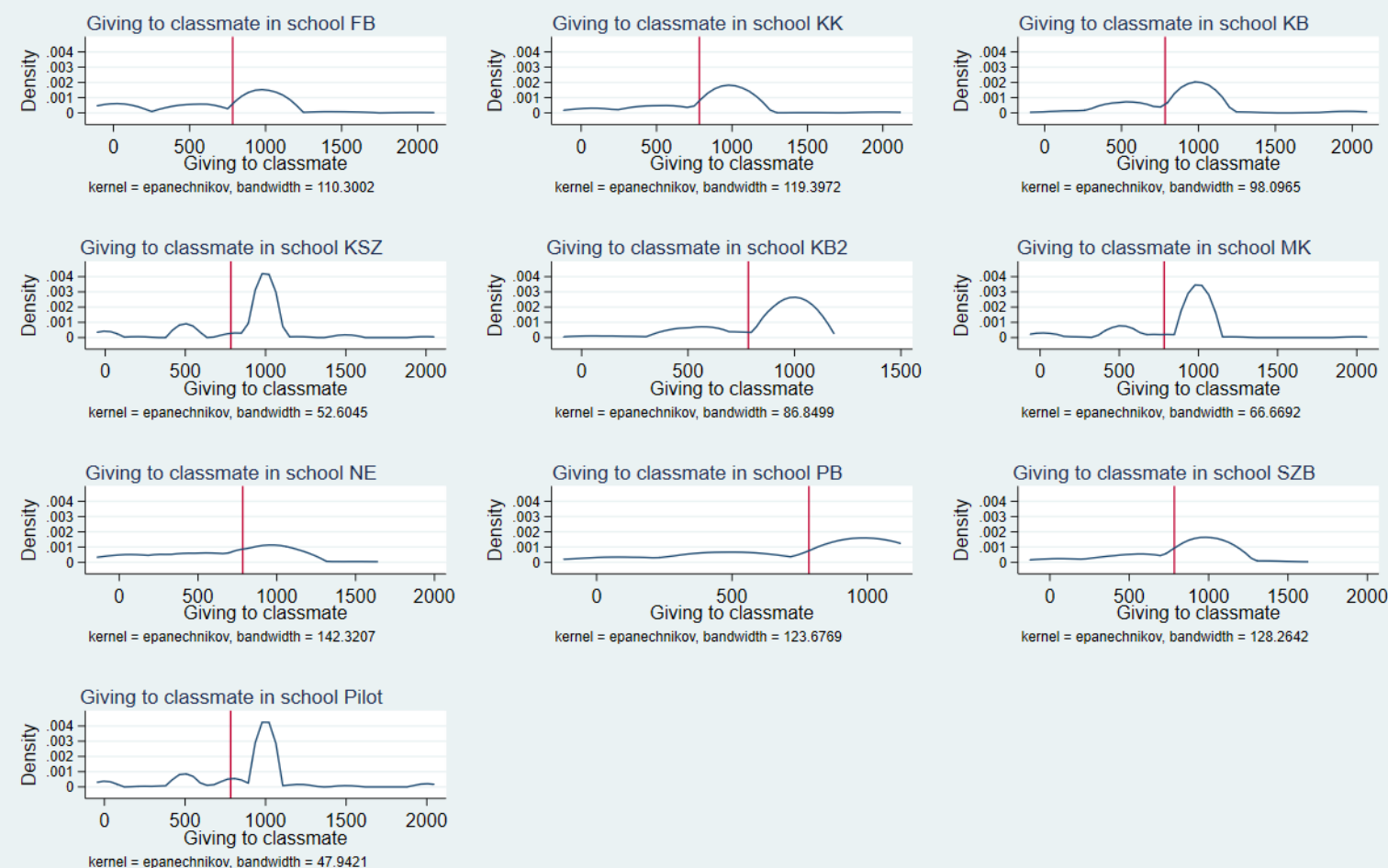

kernel $=$ epanechnikov, bandwitth $=123.6769$

kernel $=$ epanechnikov, bandwidth $=128.2642$

Red line: sample mean without the Pilot school: 783.65

\section{Giving to schoolmate, by school}
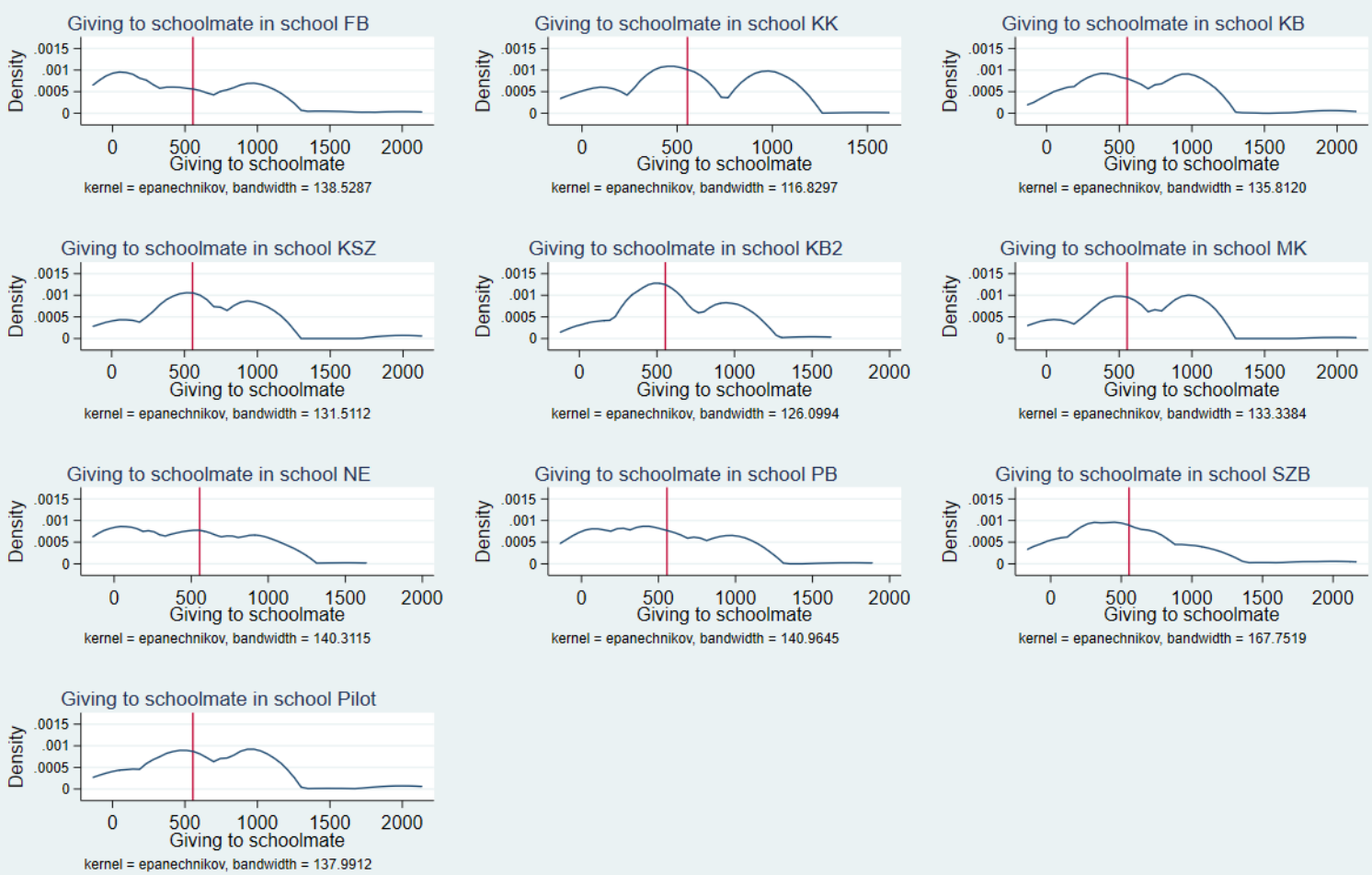

Red line: sample mean without the Pilot school: 554.68 


\section{Cooperation: contribution, by school}
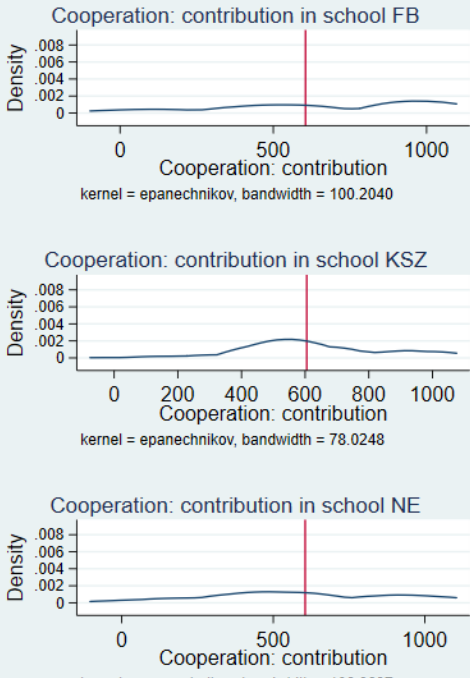

kernel $=$ epanechnikov, bandwidth $=106.8697$

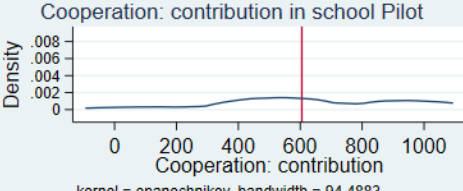

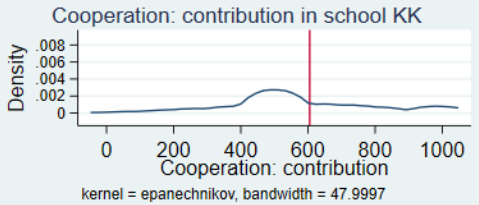

Cooperation: contribution in school KB2

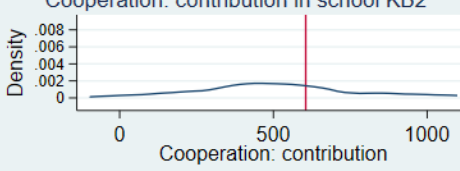

kernel $=$ epanechnikov, bandwidth $=98.3089$

Cooperation: contribution in school PB

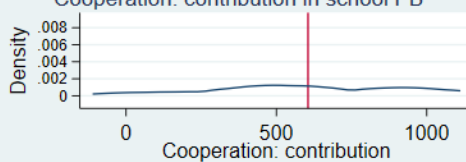

kernel $=$ epanechnikov, bandwidth $=111.8845$

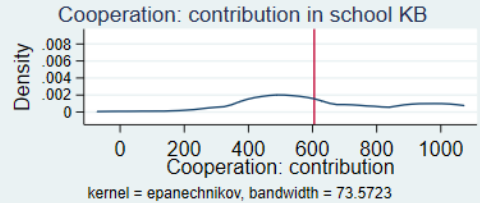

Cooperation: contribution in school MK

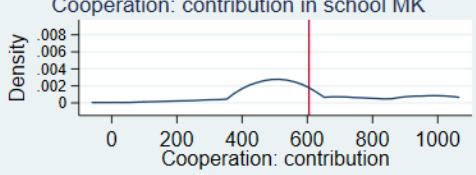

kernel $=$ epanechnikov, bandwidth $=66.6692$

Cooperation: contribution in school SZB

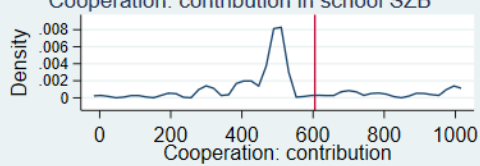
kernel $=$ epanechnikov, bandwidth $=17.1144$

Red line: sample mean without the Pilot school: 605.13

\section{Trust: sum sent, by school}

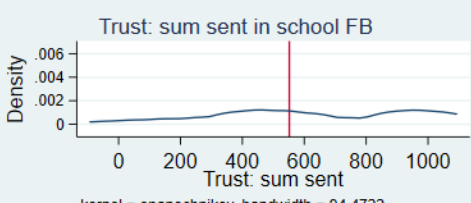

kernel = epanechnikov, bandwidth $=94.4722$

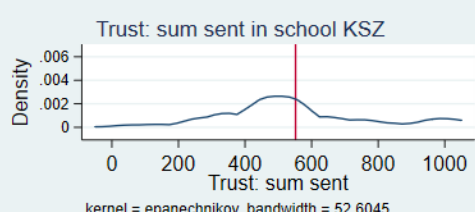

kernel $=$ epanechnikov, bandwidth $=52.6045$

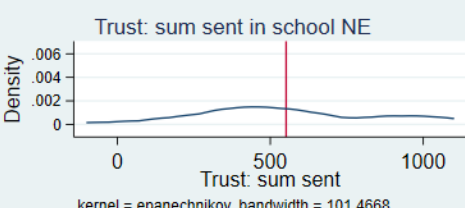

kernel $=$ epanechnikov, bandwidth $=101.4668$

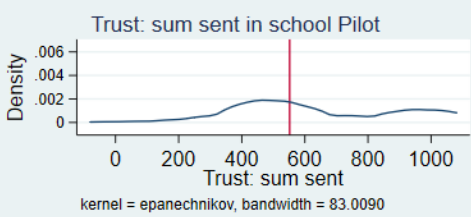

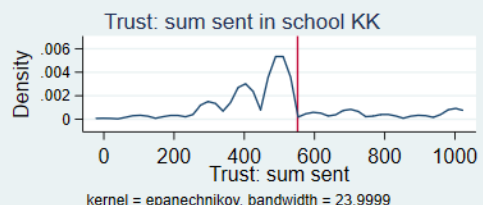

kernel $=$ epanechnikov, bandwidth $=23$ g999

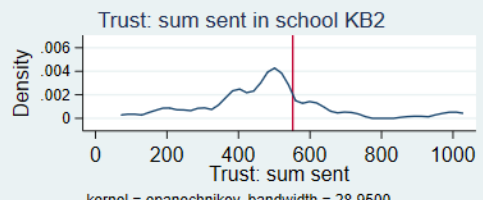

kernel $=$ epanechnikov, bandwidth $=28.9500$

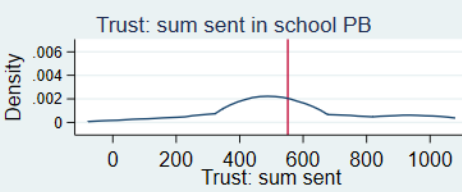

kernel $=$ epanechnikov, bandwidth $=79.8408$
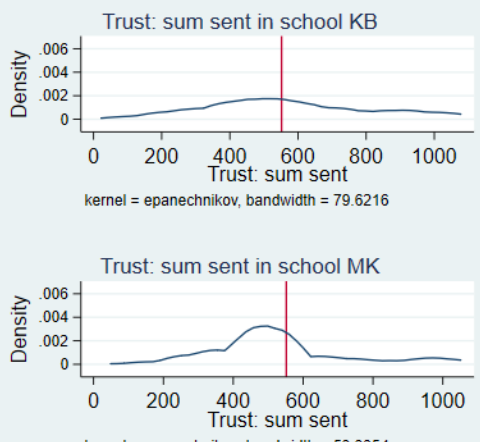

kernel $=$ epanechnikov, bandwidth $=53.335$

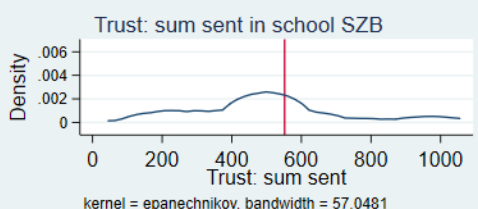

Red line: sample mean without the Pilot school: 551.8 


\section{Trust: \% returned, by school}
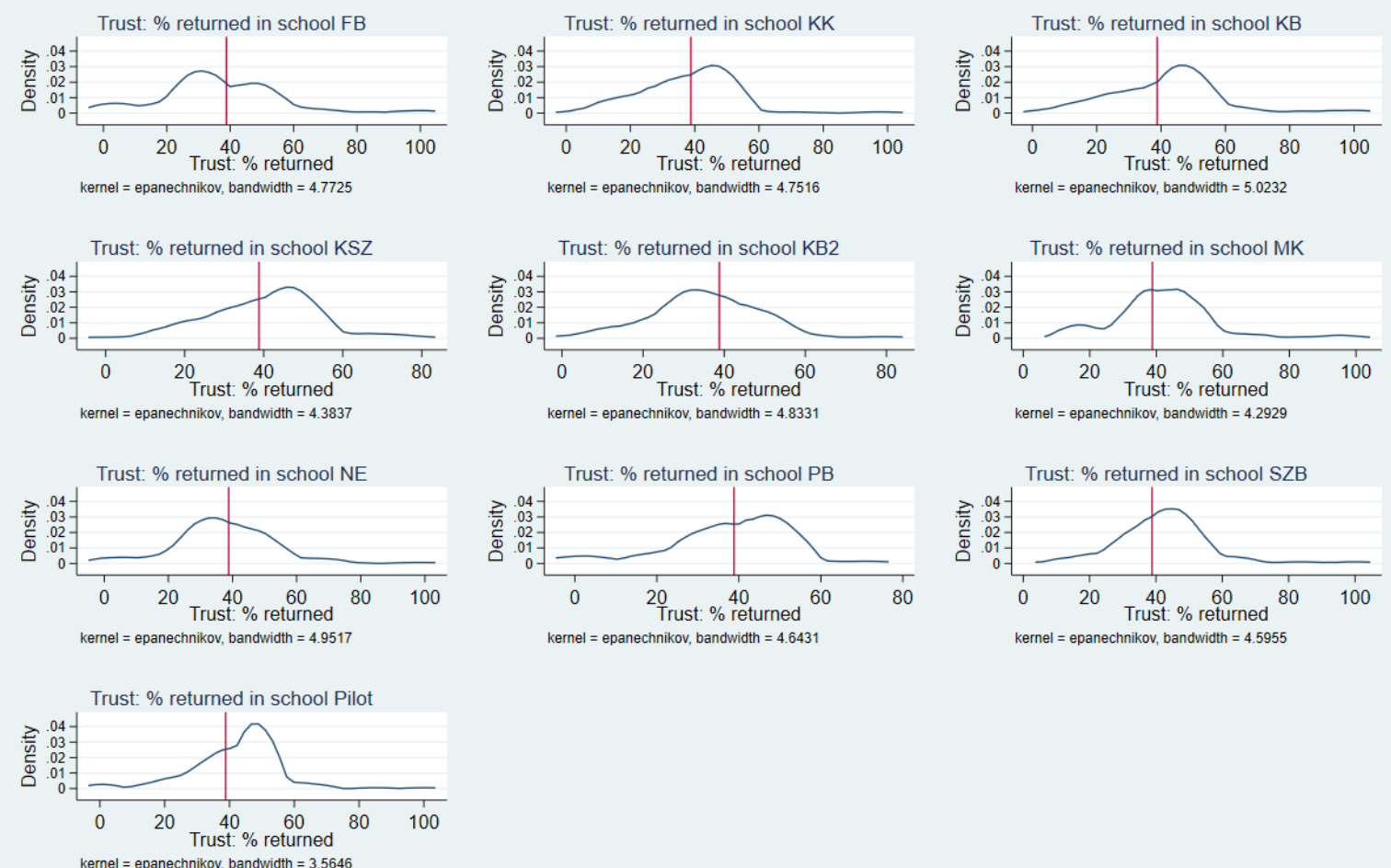

Red line: sample mean without the Pilot school: 38.81 